Article

\title{
Towards a Traceable Climate Service: Assessment of Quality and Usability of Essential Climate Variables
}

\author{
Yijian Zeng 1,*(-), Zhongbo Su ${ }^{1, *}$, Iakovos Barmpadimos ${ }^{2}$, Adriaan Perrels $\left.{ }^{3}{ }^{(}\right)$, Paul Poli ${ }^{4}(\mathbb{D}$, \\ K. Folkert Boersma ${ }^{5,7}{ }^{\circledR}$, Anna Frey ${ }^{3}$, Xiaogang Ma ${ }^{6}{ }^{\oplus}$, Karianne de Bruin ${ }^{7}$, Hasse Goosen ${ }^{7}$, \\ Viju O. John ${ }^{8}{ }^{\circ}$, Rob Roebeling ${ }^{8} \mathbb{D}$, Jörg Schulz ${ }^{8}$ and Wim Timmermans ${ }^{1}$ \\ 1 Faculty of Geo-information and Earth Observation (ITC), University of Twente, Hengelosestraat 99, \\ 7514 AE Enschede, The Netherlands; w.j.timmermans@utwente.nl \\ 2 SCOR Global P\&C, Guisan-quai 26, 8002 Zurich, Switzerland; ibarmpadimos@scor.com \\ 3 Finnish Meteorological Institute, Erik Palménin aukio 1, FI-00560 Helsinki, Finland; \\ Adriaan.Perrels@fmi.fi (A.P.); Anna.Frey@fmi.fi (A.F.) \\ 4 Meteo-France, Centre de Meteorologie, Marine, SHOM, 13 Rue de Châtellier, 29200 Brest, France, \\ paul.poli@shom.fr \\ 5 The Royal Netherlands Meteorological Service, Utrechtseweg 297, 3731 GA De Bilt, The Netherlands; \\ folkert.boersma@knmi.nl \\ 6 Department of Computer Science, University of Idaho, 875 Perimeter Drive, Moscow, ID 83844, USA; \\ max@uidaho.edu \\ 7 Stichting Wageningen Research, Wageningen Environmental Research, Droevendaalsesteeg 3-3 A, \\ 6708 PB Wageningen, The Netherlands; karianne.debruin@wur.nl (K.d.B.); hasse.goosen@wur.nl (H.G.) \\ 8 European Organisation for the Exploitation of Meteorological Satellites (EUMETSAT), Eumetsat Allee 1, \\ 64295 Darmstadt, Germany; Viju.John@eumetsat.int (V.O.J.); Rob.Roebeling@eumetsat.int (R.R.); \\ Joerg.Schulz@eumetsat.int (J.S.) \\ * Correspondence: y.zeng@utwente.nl (Y.Z.); z.su@utwente.nl (Z.S.)
}

Received: 7 April 2019; Accepted: 16 May 2019; Published: 18 May 2019

\begin{abstract}
Climate services are becoming the backbone to translate climate knowledge, data \& information into climate-informed decision-making at all levels, from public administrations to business operators. It is essential to assess the technical and scientific quality of the provided climate data and information products, including their value to users, to establish the relation of trust between providers of climate data and information and various downstream users. The climate data and information products (i.e., from satellite, in-situ and reanalysis) shall be fully traceable, adequately documented and uncertainty quantified and can provide sufficient guidance for users to address their specific needs and feedbacks. This paper discusses details on how to apply the quality assurance framework to deliver timely assessments of the quality and usability of Essential Climate Variable (ECV) products. It identifies an overarching structure for the quality assessment of single product ECVs (i.e., consists of only one single variable), multi-product ECVs (i.e., more than one single parameter), thematic products (i.e., water, energy and carbon cycles), as well as the usability assessment. To support a traceable climate service, other than rigorously evaluating the technical and scientific quality of ECV products, which represent the upstream of climate services, how the uncertainty propagates into the resulting benefit (utility) for the users of the climate service needs to be detailed.
\end{abstract}

Keywords: climate data record (CDRs); essential climate variables (ECVs); quality assurance; traceability; usability assessment; climate services 


\section{Introduction}

Climate services, emerging from a process of transforming climate science into bespoke information products and decision-support for society, have been mainstreamed with significant initiatives at the global scale (e.g., the Global Framework for Climate Services) [1,2], regionally in Europe (e.g. Copernicus Climate Change Service (C3S), ClimateKIC, or Climate-Adapt portal), and nationally through the emergence of national climate service centers [3]. There are various definitions and interpretations for the concept of climate services, and it is not until recently the European Commission established an ad hoc Expert Group, assigning the climate services a broad meaning [4]: "the transformation of climate-related data - together with other relevant information -into customised products such as projections, forecasts, information, trends, economic analysis, assessments (including technology assessment), counselling on best practices, development and evaluation of solutions and any other service in relation to climate that may be of use for society at large". From the definition, the climate services encompass the whole spectrum including climate data, information, and knowledge (e.g., that support adaptation, mitigation, and disaster risk management), as well as the service demand side and the evaluation of the services.

For example, the C3S aims to be an authoritative source of climate information about the past, current and future states of the climate in Europe and worldwide, and targets the commercial use of climate data and derived information products to flourish the market for climate services in Europe [5]. The target of supporting a European market for climate services is also advocated by the European Commission (EC) (e.g., identified as "flagship initiatives" via Horizon 2020) [4] and other transnational, national and regional programs [3]. As one major component of the C3S architecture, the Evaluation and Quality Control (EQC) function assesses the technical and scientific quality of the service including the value to users. The EQC function is the quality assurance tool to evaluate if the data is "climate compliant" or not, and to assess how much extent the tailored climate service meets users' specific needs (i.e., fitness for purpose). With EQC, it is expected that the climate information is fully traceable, adequately documented and uncertainty quantified (i.e., climate compliant) and can provide sufficient guidance for users to address their specific needs and feedbacks. The EQC function is the key to ensuring the climate information is authoritative, whether produced by C3S or not, and to establish relations of trust between climate information providers and various downstream users. As such, the EQC function contributes to the implementation of a "European Research and Innovation Roadmap for Climate Services", by addressing its challenges of "Building the Market Framework" and "Enhancing the Quality and Relevance of Climate Services" [6].

The above two challenges have inspired two main groups of research focuses: (1) the quality assurance of climate data and information products (e.g., QA4ECV [7], QA4EO [8], GAIA-CLIM [9], FIDUCEO [10], CORE-CLIMAX [11], C3S EQC projects [12-16]); (2) the market value of climate services (EU-MACS [17,18], MARCO [18,19], EUPORIAS [20], C3S Sectoral Information System Projects [21]) (see the Appendix A for a list of key acronyms and abbreviations used in this paper). The prototyped quality assurance (QA) framework for climate data records has been recently developed [22] and implemented for a selection of 12 Essential Climate Variables (ECVs), with in total 24 products [23]. Nevertheless, the evaluation of the usability of climate data and information products is not yet comprehensively addressed, which hinders the overall market uptake of climate services [24,25]. The market of climate services, although gaining its popularity, remains in its infancy and the associated economic benefits/values to users are either unknown or uncertain [18], which is mainly due to the lack of exploration into the uncertainty propagation in the so-called value chain of climate services [26]. While the necessity of evaluating climate services is well recognized, to ensure its success (e.g., useful/usable for decision making at all levels) and continuous evolutions, the effective metrics, methodologies, and associated evaluation framework are still to be further developed and matured [26,27].

The value chain of climate services is complicated; the main feature of which can be deemed as a stage-wise process [28]. A crude distinction is by upstream, midstream and downstream services. Upstream climate services involve the reprocessing and fusion of (different) observational data, as well 
as development and application of various types of climate models and reanalysis products $[29,30]$. The EQC projects/efforts are currently concentrating on the upstream for the ECV climate data records (CDRs). In the upstream part the role of non-climate data is small (e.g., socio-economic, demography, land cover land use change, etc.), and these non-climate data are still of (geo) physical nature. The users of these climate services are mostly operating in the midstream part (e.g., climate indicators, downscaling to local scale and evaluating impacts, etc.). However, for some sectors, such as electricity supply, it may stretch from the upstream of available climate data and information to the downstream of end-use applications.

In the midstream part, advanced downscaling (i.e., from global to local scale), complex composite (climate) variables, and impact-oriented indicators are developed (e.g., involving more biological data), and also applications and data platforms are developed with particular downstream applications in mind (such as for public health risks and technical infrastructure management). This means that the data products tend to contain more non-climate data, purpose-developed composites, and specific climate data-based indicators. The design of these climate indicators requires knowledge about processes outside climate. The users of these climate services are operating in the midstream and downstream, either as end-users or as end-user-oriented organizations.

In the downstream segment, the significance of non-climate data increases. Furthermore, various end-use segments may not have very formalized risk assessment and decision procedures in place. All in all, this makes a purely quantitative QA application difficult or impossible in this segment. Transparent QA in the preceding stages of climate service value chain can make QA easier at this downstream stage. Nevertheless, the evaluation of the complete chain of climate services needs consideration on aspects (e.g. user-driven, communication, socioeconomic efficiency and social and behavioral sciences) beyond the EQC alone $[27,31]$. Furthermore, other than the assessment of the quality of ECVs, the evaluation of the usability of ECVs should be addressed as well [32]. In this study, we will focus on the evaluation procedures for ECVs, addressing their technical and scientific quality as well as its usability, and taking into account the current development of climate service initiatives in Europe.

The ECV products are typically derived from Earth Observations (satellite and in-situ) and reanalysis products, including single-product ECVs (i.e., consists of only one single ECV variable), multi-product ECVs (i.e., more than one single ECV variables, for example cloud properties) and thematic products (i.e., physically interlinked ECV variables) [33,34]. The generation of ECV CDRs usually needs to combine data from a variety of sources (e.g., space, in-situ and reanalysis) and to go through various steps of a production chain $[29,35,36]$. The present paper reviews and synthesizes the academic literature on the quality assurance of ECVs, and describes the details on how to evaluate the quality, and usability of ECV products. In the following sections, the overarching structure is firstly introduced for single-product assessment, multi-product inter-comparison, thematic assessment and usability assessment, followed by separate sections of delineating each assessment. More specifically, for usability assessment, a reinsurance example was used to demonstrate how different climate data can lead to different economic values of climate services. The final section provides general conclusions and recommendations.

\section{Overarching Structure for the Assessment of Quality and Usability (AQUE) of ECV Products}

The Conference of the Parties (COP)-21 Paris Agreement calls to "strengthen scientific knowledge on climate, including research, systematic observation of the climate system and early warning systems, in a manner that informs climate services and supports decision-making" [37], which assembles the pressing needs of the United Nations Framework Convention on Climate Change (UNFCCC) and the Global Climate Observing System (GCOS) for systematic climate observations. Observations are the basis for detecting climate trends, as well as for the understanding of climate processes (i.e., water, energy and carbon cycles) that enable climate modeling and prediction. Against a backdrop of human-induced climate change, some climate variables shift their probability distributions with increases in the likelihood of "climate extremes" (e.g., heat waves and heavy rainfall events), which 
can be only reliably detected using observations, and poses additional challenges for monitoring, modeling and predicting the climate system. Improved knowledge of these challenges is a prerequisite for adaptation and mitigation decisions, effective disaster risk reduction, and therefore climate services.

To characterize and trace climate change, GCOS defined the Essential Climate Variables (ECVs) and provided an internationally agreed priority list to guide the sustained observation of the Earth's climate [33,38]. GCOS aims to collect the accurate and homogeneous Climate Data Records (CDRs) over long timescales. It is notable that the observational signals that are important for climate monitoring and the detection of climate variability and change can easily be lost in the "noise" of an evolving observing system. Such "noise" emphasizes the need for a sustainable continuity in an observing system that can be gauged against an invariant reference. To ensure in-place of such observing system, WMO (World Meteorological Organization) developed the GCOS climate monitoring principles for establishing the climatology of traditional meteorological parameters from the ground using standard meteorological stations [39]. Nevertheless, for global observations of Earth's climate and of all GCOS ECVs, a multitude of observation systems is required, and both in-situ observations and remote-sensing instruments flown on airborne or satellite platforms are indispensable [38].

The free and open access to essential climate data and information, including the fully traceable accuracy information of these ECV CDRs, as well as user feedback mechanisms, is critically important for effective climate services. It is only when the fully traceable accuracy information of ECV CDRs meet the end-user defined achievable accuracy requirements, that we can deem the climate services as useful [26]. To provide a structured and holistic view on what CDRs are currently available/planned, and what the accuracy requirements should be to satisfy climate quality, the joint CEOS /CGMS Working Group on Climate (WGClimate) has established an ECV inventory [40]. The ECV inventory will subsequently make up the structure of the climate monitoring architecture for space-based observations [11,29]. This will be realized through the gap analysis to identify shortfalls and potential improvements for both current and future CDRs. The cyclic gap analysis (see Figure 1, "Single Product Assessment") is a sustainable mean to update ECV CDRs to meet GCOS' evolving observation requirements [41,42]. The ECV inventory is essential for realizing the high-quality, reliable and timely climate services.

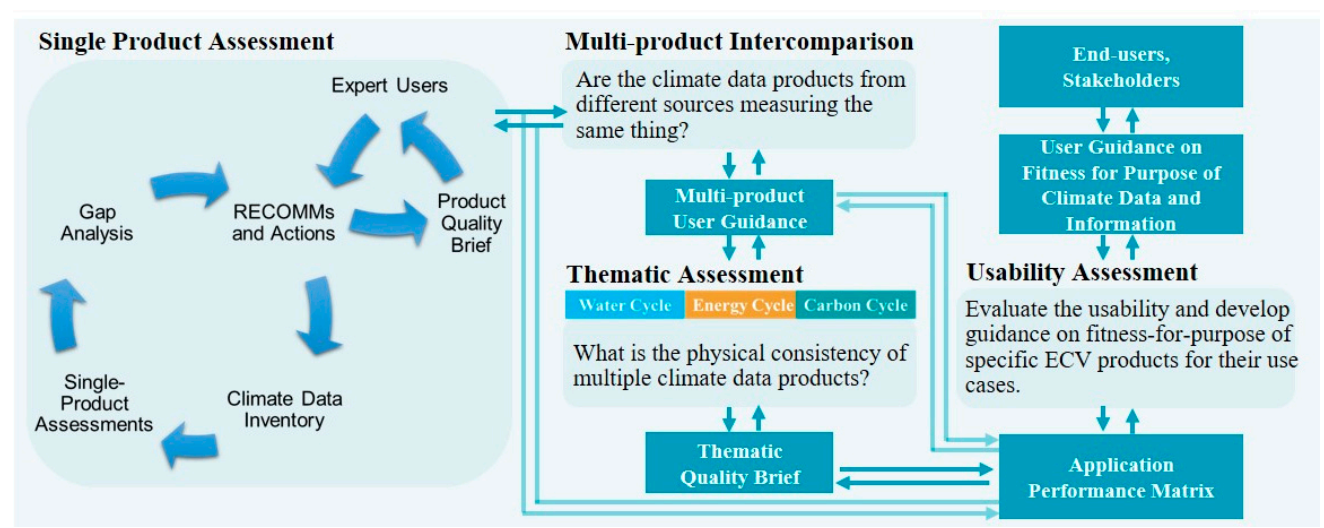

Figure 1. Overarching structure for the assessment of quality and usability of Essential Climate Variable (ECV) products (incl. single-products, multi-products and thematic products, as well as user-provider feedback mechanisms). (RECOMMs-Recommendations).

Nevertheless, the ECV inventory only addresses the single-product ECVs, and is not meant to address specific applications, nor to address the multi-product ECVs and thematic products. It is notable that the ECV inventory was not designed to quantify the confidence in existing data products for specific climate-sensitive societal sectors (e.g., water and food security, water management, and health). Such usability assessment requires the integrated use of climate data and effective user-provider feedback mechanisms. When there are different versions of the same ECV available from various data providers, the situation (for evaluating usability) is more complicated. Furthermore, most ECV 
products are generated with independent or multiple sources of data (e.g., including in-situ, satellite and model), and use various retrieval algorithms. These data products may also adhere to different definitions and assumptions, which is not standardized among the international communities. All these call for an overarching structure for the assessment of quality and usability of ECV products, across the single-products, multi-products and thematic products. Based on current major initiatives and studies for the development of ECV inventory [22,23,33,43-48], our paper synthesizes and proposes the overarching structure as shown in Figure 1.

It starts from the Single Product Assessment, which will be the foundation to recommend inclusion, conditional inclusion or exclusion of ECV products for serving decision making based on the needs of the downstream users. Furthermore, the single product assessment will implement a gap analysis to identify shortfalls and possible recommendations/action plans for improvement, and provide a quality brief for dissemination, including the user feedback mechanism (Figure 1). It is envisaged that estimates of the single-product ECV may come from several sources, including reanalysis, satellite products, and in-situ datasets, as well as from different international agencies, institutes and research programs. The Multi-product Inter-comparison is to investigate each source for its strengths, weaknesses, and limitations, and to answer the question: Are the ECV products from multiple sources measuring the same thing? While the original ECVs were designed mainly on the basis of individual usefulness, recent efforts have started to use the ECV CDRs to close budgets of energy, carbon and water cycles, and to study interactions between land, atmosphere, and ocean in a more integrated way $[47,49,50]$. As such, the Thematic Assessment is to document the physical consistency of multiple ECV products and to identify gaps in terms of closing the budget of cycles and where ECVs contribute to fundamental understanding of the natural processes.

With the foregoing assessments, the quality information of ECV products (i.e., single-, multi-, and thematic-products) will provide essential meta-information on datasets to inform potential users and enable the comparison of datasets, to evaluate the fitness-for-purpose (F4P) for the envisaged use cases. The Usability Assessment is to detail what the essential metadata is for the end-user, how the prospective end-user can benefit from the metadata, and, given these insights, provide feedbacks to climate services providers on the presentation and validation of metadata, as well as to specify links between quality features of ECV products and the resulting benefit (utility) for the users.

\section{Single Product Assessment}

The single-product assessments will update the CDI (Climate Data Inventory), with the best available data about the observed climate. The assessment will help the users of climate data to receive clear contextual guidance on the implications of uncertainties in that particular climate data. The single-product assessment has the following logical elements (see Figure 1): (1) Providing descriptive metadata for the ECV products (i.e., for CDI); (2) Implementing gap analysis on the ECV products to provide recommendations on inclusion, conditional inclusion, or exclusion of the ECV products in the CDI, and proposing any actions needed to implement the recommendation for improvement; (3) Providing high-level qualitative user guidance on strengths, weaknesses, and limitations of the ECV products and providing quantitative results on product uncertainties (i.e., quality brief).

The WGClimate has defined six categories essential to understanding the circumstances under which the ECV CDR was produced, including stewardship, generation process, record characteristics, documentation, accessibility, and applications [46]. The "record characteristics" serves to understand the specific features of data records (e.g., spatiotemporal extent and resolution, accuracy, sensors, etc.), while the "generation process" and "documentation" will provide information on how traceable the generation process is (i.e., metrological traceability), how adequate the documentation is (i.e., documentary traceability), as well as how the uncertainty is quantified (i.e., validation traceability). As such, the quality assessment in the present paper refers to the categories of "generation process" and "documentation," while the usability assessment belongs to the categories of "application" (discussed in Section 6). 


\subsection{Defining Product Traceability}

Traceability in the Earth observation context can be defined as "a property of an often multi-step process whereby the result can be related to its data source(s) (and ideally to international standards) through a documented unbroken chain of operations including calibrations" [8]. The first level of traceability corresponds to the documentary traceability, which refers to the provision of detailed provenance information or metadata concerning product development [22]. The metrological traceability extends further to encompass a full analysis of the propagation of uncertainties from end-to-end through the algorithm and validation stages [22].

The product traceability can be implemented with a top-down approach, which is a forward processing from a producer (or expert-user) point of view on (a) how ECVs have been produced; (b) what are the underlying assumptions; (c) where the input data is coming from. As such, one can trace back the ECV production chain and obtain provenance information of interest [22]. There is also "backward processing" approach, which can further support and ease this top-down approach and add machine-readability to the ECV products. This "backward processing" will enable collecting agilely the provenance information from scientific reports, peer-review journals and project documentations, and trace back to the origin of the ECV CDR processing chain. This is particularly useful for a non-expert user, for example, who does not necessarily have the exact knowledge on how to do atmospheric corrections.

Figure 2 shows an example of how to collect provenance information from peer-review journal articles and distributed data sources for the global sea-level rise scenarios. From the published paper, with the GCIS (Global Change Information System) information model and corresponding ontology model [51,52], the climate data behind the Figure "Global sea-level rise" was traced back to the raw dataset and platforms.

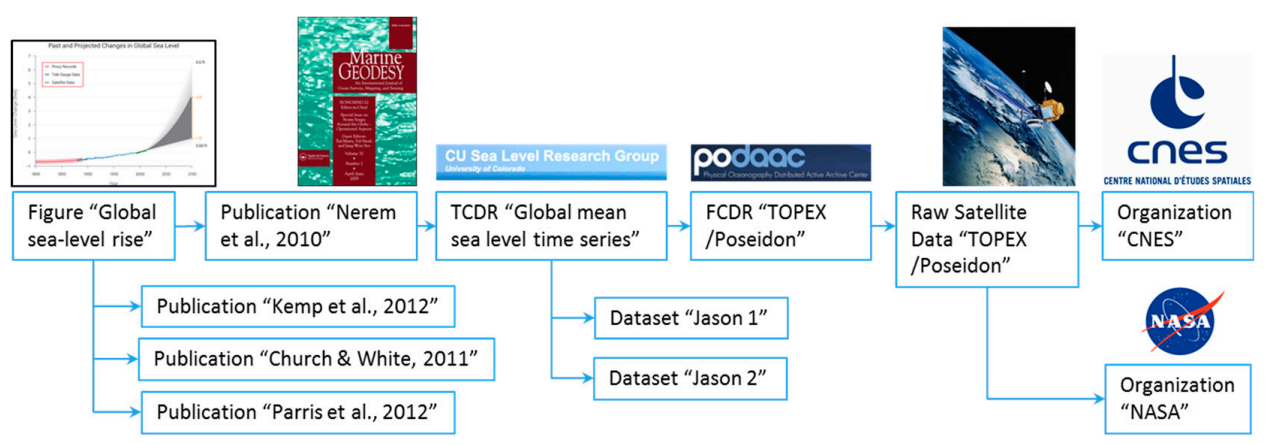

Figure 2. Tracing CNES' and NASA's contribution to the global sea-level rise scenario results. The example here is from real-world records but is presented in a condensed manner. It shows several objects and steps involved in the generation of the "global sea-level rise scenarios", and traces back to the raw dataset and platforms at CNES and NASA. Each resource in this traceability chain has a specific type that is defined in the GCIS ontology. As such, the provenance information in the ECV Climate Data Record (CDR) Production chain will be collected agilely.

Although the documentary traceability can be assessed with an information model like GCIS, it is still difficult to evaluate the metrological traceability. It is currently feasible for a limited number of space-based atmosphere ECV products to trace back uncertainty metrologically. However, such traceability is not yet feasible in other domains or for in-situ based ECVs [22,53,54]. The main factors causing this difficulty (e.g., not yet applicable to trace all space-based ECV products) include difficulties associated with relating Level 1 satellite data back to SI standards and the complexity of expressing uncertainties through a generalized classification scheme. Also, the production of most of ECVs involves an array of atmospheric or surface correction codes, and there is currently no unified definition of accuracy/stability requirements $[55,56]$. Nevertheless, the gap analysis on these perspectives against the generalized Architecture for Climate Monitoring from Space (ACMS) [29] will 
help to identify potential actions needed towards a generalized evaluation of metrological traceability for all space-based ECV products.

\subsection{Validation Traceability Quality Indicator (ValQI)}

To establish the traceability of a validation process, documenting each step of the validation process is required. According to the analysis of current validation practices in Europe for the space-based, in-situ and reanalysis products, CORE-CLIMAX identified a generic validation strategy [54] as shown in Figure 3a. Starting from documenting how the reference dataset is generated, the generic process requires the assessment of the independence level of the reference dataset. With the quality-controlled reference data, the data producer shall implement the self-assessment. For a complete validation process, it is a requirement to check the consistency of the validated CDRs.

(a)
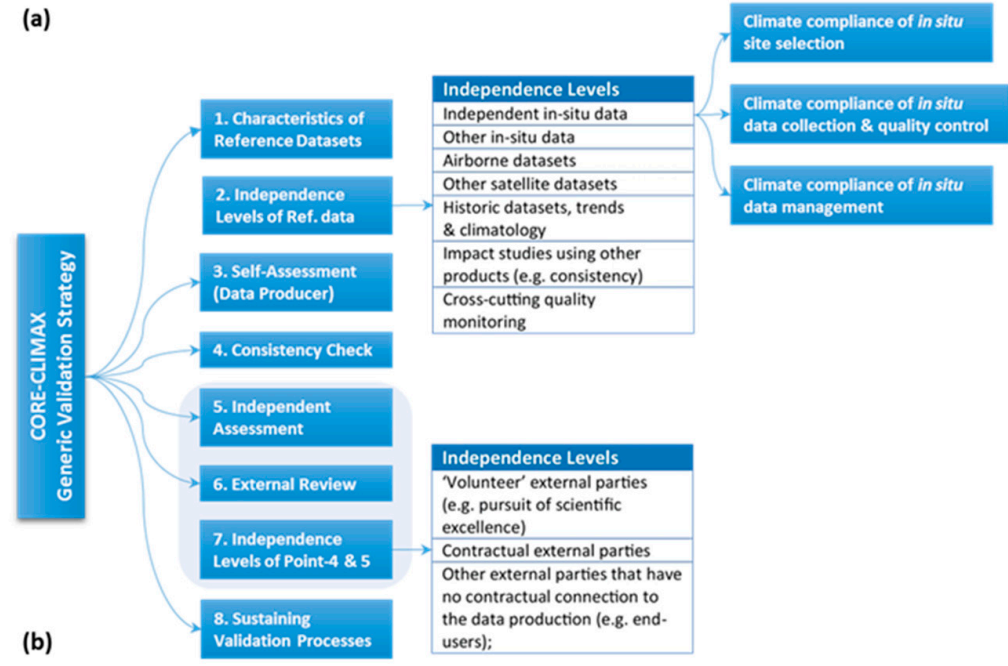

\begin{tabular}{|c|c|c|c|c|c|c|c|c|}
\hline Formal Validation Report & \multicolumn{6}{|c|}{ Validation } & \multicolumn{2}{|r|}{ Generic Validation Process } \\
\hline & & & & & & & \multicolumn{2}{|r|}{$\begin{array}{l}\text { 1. The generation of } \\
\text { independent reference data; } \\
\text { 2. Assessing independence } \\
\text { levels of reference data; }\end{array}$} \\
\hline $\begin{array}{l}\text { Report on limited validation available } \\
\text { from Principle Investigator (PI) }\end{array}$ & \multicolumn{7}{|c|}{$\begin{array}{l}\text { Validation using external reference data done for } \\
\text { limited locations and times }\end{array}$} & 3. Self-assessment; \\
\hline $\begin{array}{l}\text { Report on comprehensive validation } \\
\text { available from PI; Paper on product } \\
\text { validation submitted }\end{array}$ & \multicolumn{7}{|c|}{$\begin{array}{l}\text { Validation using external reference data done for } \\
\text { global and temporal representative locations and } \\
\text { times (e.g. spatio-temporal consistency) }\end{array}$} & \\
\hline $\begin{array}{l}\text { Report on inter-comparison to other } \\
\text { CDRs, etc. Available from PI and data } \\
\text { Provider; Journal paper on product } \\
\text { validation published }\end{array}$ & \multicolumn{6}{|c|}{$\begin{array}{l}\text { Score } 3+\text { (Inter)comparison against corresponding } \\
\text { CDRs (other methods, models, other physically } \\
\text { interlinked CDRs etc.) }\end{array}$} & & \\
\hline $\begin{array}{l}\text { Score } 4+\text { Report on data assessment } \\
\text { results exists }\end{array}$ & \multicolumn{6}{|c|}{$\begin{array}{l}\text { Score } 4+\text { data provider participated in one inter- } \\
\text { national data assessment }\end{array}$} & \multicolumn{2}{|r|}{\begin{tabular}{|l|} 
5. Independent assessment; \\
$\begin{array}{l}\text { 6. External review of self- } \\
\text { assessment; }\end{array}$ \\
$\begin{array}{l}\text { 7. Assessing independence } \\
\text { levels of point } 5 \& 6 ;\end{array}$ \\
\end{tabular}} \\
\hline $\begin{array}{l}\text { Score } 5+\text { Journal papers more } \\
\text { comprehensive validation, e.g., error } \\
\text { covariance, validation of qualitative } \\
\text { uncertainty estimates published }\end{array}$ & \multicolumn{6}{|c|}{$\begin{array}{l}\text { Score } 4+\text { data provider participated in multiple } \\
\text { inter-national data assessment and incorporating } \\
\text { feedbacks into the product development cycle }\end{array}$} & & $\begin{array}{l}\text { 8. Sustaining established } \\
\text { processes \& methods. }\end{array}$ \\
\hline \multicolumn{9}{|l|}{ (c) } \\
\hline Validation Quality Indicator (ValQI) of & f CORE-CUMAX SMM & $\mathbf{L}$ & 12 & 13 & 14 & 15 & & Level 1 \& 2 \\
\hline \multicolumn{2}{|r|}{ User Documentation } & & & & & & \multirow{4}{*}{\multicolumn{2}{|c|}{$\begin{array}{l}\text { Research Capability } \\
\text { Level } 3 \& 4 \\
\text { Initial Operations } \\
\text { Capability }\end{array}$}} \\
\hline \multicolumn{2}{|c|}{ Formal description of scientific methodology } & $\checkmark$ & $\checkmark$ & $\checkmark$ & $\checkmark$ & $\checkmark$ & & \\
\hline \multicolumn{2}{|c|}{ Formal Validation Report } & $\checkmark$ & $\checkmark$ & $\checkmark$ & $\checkmark$ & & & \\
\hline \multicolumn{2}{|c|}{ Formal Product User Guide } & 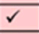 & $\checkmark$ & $\checkmark$ & 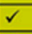 & $\checkmark$ & & \\
\hline Formal description of & f operations concept & $\checkmark$ & $\checkmark$ & $\checkmark$ & $\checkmark$ & & \multirow{6}{*}{\multicolumn{2}{|c|}{$\begin{array}{l}\text { Level } 5 \text { \& } 6 \\
\text { Full Operations } \\
\text { Capability }\end{array}$}} \\
\hline \multicolumn{2}{|c|}{ Uncertainty Characterization } & & & & & & & \\
\hline & Standards & $\checkmark$ & 2 & $\checkmark$ & 2 & 2 & & \\
\hline & Validation & $\checkmark$ & $\checkmark$ & $\checkmark$ & $\checkmark$ & $\checkmark$ & & \\
\hline Uncert & tainty quantification & $\checkmark$ & $\checkmark$ & $\checkmark$ & $\checkmark$ & $\checkmark$ & & \\
\hline Automated & Quality Monitoring & $\checkmark$ & $\checkmark$ & $\checkmark$ & $\checkmark$ & $\checkmark$ & & \\
\hline
\end{tabular}

Figure 3. (a) CORE-CLIMAX generic validation strategy for space-based ECV CDRs; (b) Validation Traceability Quality Indicator (ValQI): mapping the CORE-CLIMAX generic validation process to the 
sub-thematic areas of CORE-CLIMAX system maturity matrix: "Validation" and "Formal Validation Report"; (c) example of applying ValQI for evaluating the validation maturity of ESA-CCI Soil Moisture CDR (Phase I). The above evaluation indicates that the automated quality monitoring of ESA-CCI Soil Moisture has been partially implemented but the resulting quality feedback has not yet been incorporated into metadata or documentation. The assessment helps the ESA-CCI Soil Moisture Project team to identify the potentially needed and targeted studies to improve the climate quality of their soil moisture products.

Furthermore, it is recommended to apply the independent assessment of the CDR products, as well as the external review of the validation process, to assure the understanding of data quality. It is further required to evaluate the independence level of the independent assessment and the external review (see Figure 3a). The last step is to sustain the established validation facilities and procedures. This final step means achieving an operational validation level, at which validation activities and data release are regularly/routinely implemented.

The generic validation strategy presented above can be mapped to the CORE-CLIMAX system maturity matrix (SMM) [11,57], under the "Formal Validation Report" and "Validation" in the subthemes of "User documentation" and "Uncertainty characterization," respectively. This mapping indicates the applicability of using the corresponding validation-relevant subthemes of SMM as the quality indicator for validation traceability (i.e., ValQI) for assessing how far the validation process is approaching the "best practice" (Figure 3b) [54]. The ValQI can evaluate the maturity of existing validation processes of ECV products, in a way to identify the potentially needed and targeted studies to improve the quality of ECV products. Figure 3c shows an example of how the ValQI is used to evaluate the validation process of ESA-CCI soil moisture (Phase I). It helps to identify the potential actions needed to further improve the climate quality of the soil moisture products.

\section{Multi-Product Inter-Comparison}

It is envisaged that the single-product may come from multi-sources. For those single-products with low ValQI scores, they should be compared with one common invariant reference data to assess their uncertainties quantitatively. The inter-comparison of the multi-source single-products aims to answer the question: Are the ECV products from different sources measuring the same thing? and to provide guidance on the use of a set of products available for a single ECV parameter.

The single product assessment will formulate an inventory to present the available products and sources in a systematic way (e.g., reorganized as a multi-product inventory), providing the first level of information needed for the inter-comparison. Subsequently, to demonstrate the value of those ECV products (e.g., for climate services), the typical use cases for each product or combination of products should be described, based on the consolidated user requirements. To further assist users, one should provide high-level qualitative user guidance on the use of these products, via the readily accessible key QA characteristics of products from the multi-product inventory, as well as via applying a prototyped Application Performance Matrix (APM) developed in CORE-CLIMAX [57].

\subsection{Multi-Product Inventory}

Incomplete prior knowledge of how each ECV product was derived can lead to mistakes in the interpretation of (the quality of) ECV products. It is fundamental to provide a standard description of essential characteristics of the individual datasets, and to collate/present the information from multiple datasets in a way to facilitate a "descriptive product comparison". As such, the descriptive inter-comparison will assist end-users with the first level of critical information for their selection of ECV products. 
Table 1 shows an example of "descriptive product comparison" for a selection of upper-air temperature products from multiple sources (i.e., satellite, in-situ and reanalysis). It is straightforward to see that the spatial resolutions (either horizontal or vertical) are very different from each other, as are the different filtering (bias correction) techniques to reduce random (systematic) noise/errors. Such first level information provides the comprehensive knowledge of how each product was produced, reducing the likelihood of erroneous interpretations of inter-comparison results. As such, this descriptive comparison is compellingly important, considering the broad ranges of products from in-situ, satellites and reanalysis. The coordinated collection of the critical information (e.g. a common and readily accessible database/CDI) of the ECV product will enable the subsequent synthesis into a tabular comparison for each product or combination of products [58].

The meaningful interpretation of uncertainties requires more knowledge of how each product was derived, in particular regarding resolution, representativeness and specific domain area of validity, other than identifying the systematic and random components [55]. For example, two reanalysis or CDRs may use slightly different land-sea masks, and a careful comparison requires considering only aspects of matching characteristics in all datasets to avoid misinterpretation. In such a situation, it is helpful for users to have access to information about the land-sea masks, either in the form of figures or in the form of the data plus auxiliary tools to examine areas of interest specific to their applications (e.g., coastal areas and cities). 
Table 1. Example of "descriptive product comparison" for a selection of upper-air temperature products from multiple sources [58] (see Appendix A for acronyms,

T-Truncation in "spectral models" that use spherical harmonics).

\begin{tabular}{|c|c|c|c|c|c|c|}
\hline ECV Attribute & RSS v3.2 & $\mathrm{RICH}$ & MERRA & NOAA-CIRES 20CRv2 & ERA-Interim & ERA-20C Ensemble \\
\hline Type of Product & $\begin{array}{l}\text { Satellite Observation-based } \\
\text { CDR }\end{array}$ & In Situ Observation-based CDR & Atmospheric Reanalysis & Atmospheric Reanalysis & Atmospheric Reanalysis & Atmospheric Reanalysis \\
\hline Time Range & 1979-present & 1958-present & 1979-present & $1871-2012$ & 1979-present & 1899-2010 \\
\hline Observation Input & $\begin{array}{l}\text { Microwave Sounder Radiance } \\
\text { (MSU, AMSU-A) }\end{array}$ & Radiosonde Temperature & $\begin{array}{c}\text { Comprehensive set of } \\
\text { observations, including in } \\
\text { situ and satellite for land and } \\
\text { ocean surfaces and the } \\
\text { upper-air }\end{array}$ & $\begin{array}{l}\text { Surface pressures, and } \\
\text { sea-surface forcing } \\
\text { (temperature and ice } \\
\text { cover) }\end{array}$ & $\begin{array}{c}\text { Comprehensive set of } \\
\text { observations, including } \\
\text { in situ and satellite for } \\
\text { land and ocean surfaces } \\
\text { and the upper-air }\end{array}$ & $\begin{array}{l}\text { Surface pressures, } \\
\text { marine surface winds, } \\
\text { and sea-surface forcing } \\
\text { (temperature and ice } \\
\text { cover) }\end{array}$ \\
\hline $\begin{array}{l}\text { Product Horizontal } \\
\text { Resolution }\end{array}$ & $\begin{array}{c}2.5 \text { degree longitude } \\
\text { degree latitude }\end{array}$ & $\begin{array}{c}10 \text { degree longitude } \times 5 \text { degree } \\
\text { latitude resolution (also } \\
\text { available: individual, monthly } \\
\text { adjusted, station time-series, } \\
\text { usually twice-daily) }\end{array}$ & $\begin{array}{c}2 / 3 \text { degree longitude } \\
\text { degree latitude }\end{array}$ & $\begin{array}{l}\text { T62 truncation } \\
\text { (approx. } 300 \mathrm{~km} \text { ) }\end{array}$ & $\begin{array}{l}\text { T255 truncation } \\
\text { (approx. } 80 \mathrm{~km} \text { ) }\end{array}$ & $\begin{array}{l}\text { T159 truncation } \\
\text { (approx. } 125 \mathrm{~km} \text { ) }\end{array}$ \\
\hline $\begin{array}{l}\text { Product Vertical } \\
\text { Resolution }\end{array}$ & $\begin{array}{c}3 \text { layers (middle troposphere, } \\
\text { troposphere-stratosphere, } \\
\text { lower stratosphere) }\end{array}$ & $\begin{array}{l}16 \text { levels between } 1000 \mathrm{hPa} \text { and } \\
10 \mathrm{hPa}\end{array}$ & $\begin{array}{l}72 \text { levels between surface } \\
\text { and } 0.01 \mathrm{hPa}\end{array}$ & $\begin{array}{l}28 \text { levels between } \\
\text { surface and } 10 \mathrm{hPa}\end{array}$ & $\begin{array}{l}60 \text { levels between } \\
\text { surface and } 0.1 \mathrm{hPa}\end{array}$ & $\begin{array}{l}91 \text { levels between } \\
\text { surface and } 0.01 \mathrm{hPa}\end{array}$ \\
\hline $\begin{array}{l}\text { Product Temporal } \\
\text { Resolution }\end{array}$ & Monthly & Monthly & Hourly & 3-hourly & 6-hourly & 3-hourly \\
\hline $\begin{array}{l}\text { Filtering Technique to } \\
\text { Reduce Random Noise }\end{array}$ & Averaging & Averaging & $\begin{array}{c}\text { 6-h 3DVAR data assimilation } \\
\text { with incremental analysis } \\
\text { update }\end{array}$ & $\begin{array}{c}\text { 6-h Ensemble Kalman } \\
\text { Filter }\end{array}$ & $\begin{array}{l}\text { 12-h 4DVAR data } \\
\text { assimilation }\end{array}$ & $\begin{array}{l}\text { 24-h ensemble of 4DVAR } \\
\text { data assimilations }\end{array}$ \\
\hline $\begin{array}{c}\text { Bias Correction to } \\
\text { Reduce Systematic } \\
\text { Errors }\end{array}$ & $\begin{array}{l}\text { Series of adjustments to correct } \\
\text { in particular for orbital drift, } \\
\text { viewing geometry change, } \\
\text { local time change, and } \\
\text { instrument changes }\end{array}$ & Homogenization & $\begin{array}{l}\text { Variational bias correction } \\
\text { for radiances, and other } \\
\text { schemes for in situ } \\
\text { observations (incl. } \\
\text { RAOBCORE v1.4 for } \\
\text { radiosondes temperature) }\end{array}$ & $\begin{array}{c}\text { Removal of mean } \\
\text { difference observation } \\
\text { minus forecast for past } \\
60 \text { days }\end{array}$ & $\begin{array}{c}\text { Variational bias } \\
\text { correction for radiances, } \\
\text { and other schemes for in } \\
\text { situ observations (incl. } \\
\text { RAOBCORE v1.3 for } \\
\text { radiosondes } \\
\text { temperature) }\end{array}$ & $\begin{array}{l}\text { Variational bias } \\
\text { correction for surface } \\
\text { pressures }\end{array}$ \\
\hline Main Reference & $\begin{array}{c}\text { Mears and Wentz, 2009, } \\
\text { doi:10.1175/2008JTEC_HA1176.1 }\end{array}$ & $\begin{array}{c}\text { Haimberger et al., 2012, } \\
\text { doi:10.1175/JCLI-D-11-00668.1 }\end{array}$ & $\begin{array}{l}\text { Rienecker et al., 2011, } \\
\text { doi:10.1175/JCLI-D-11-00015.1 }\end{array}$ & $\begin{array}{l}\text { Compo et al., 2011, } \\
\text { doi:10.1002/qj.776 }\end{array}$ & $\begin{array}{c}\text { Dee et al., } 2011, \\
\text { doi:10.1002/qj.828 }\end{array}$ & $\begin{array}{l}\text { Poli et al., 2013, ERA } \\
\text { Report Series } 14\end{array}$ \\
\hline
\end{tabular}




\subsection{Description of Use Cases and Product User Guidance}

The description of typical use cases for climate services shall include [44]: (1) a description of the end users' needs for climate-related information in a particular societal beneficial areas (SBAs)/sectors (i.e., from the consolidated user requirement). As such, the fundamentally needed ECV products will be identified for not only the ECV data users, but also the climate application developers, as well as those parties using the climate information for decision-making purposes; (2) an identification of key CDRs for generating climate-related information for specific applications; (3) a description of the observing/production system(s) required to generate those datasets. As such, the description of typical use cases can be mapped onto and serve as a practical demonstration of the logical structure of the Architecture for Climate Monitoring from Space (ACMS) [29] (see Figure 4 the ACMS pillars).

The upstream, midstream and downstream of climate services were mapped correspondingly atop the climate data and information flow in the ACMS. The upstream is linked to the "climate record creation and preservation" pillar, where the non-climate data (socio-economic, demography, social and behavioral science, etc.) is not involved. The midstream corresponds to the pillar on the application-oriented climate information products, including regional downscaling (i.e., from global climate models), climate impacts and socio-economic impacts [4]. The downstream includes the transition between "Applications" pillar and "Decision-Making" pillar, as connected by the "Reports and Data" flow, as well as the "Decision-Making" pillar itself (e.g., bespoke climate services for various end-user contexts). Furthermore, with the feedback mechanism, the use case will help to improve and further develop climate services to be more effective. It is to note that the ACMS (i.e., with the four pillars) is developed for space-based ECV CDRs, but not yet for in-situ CDRs. There are ongoing efforts on addressing the incorporation of independently coordinated in-situ observation networks into the ACMS, to describe the functional components of a consistent, integrated in-situ and space-based system for climate monitoring [29].

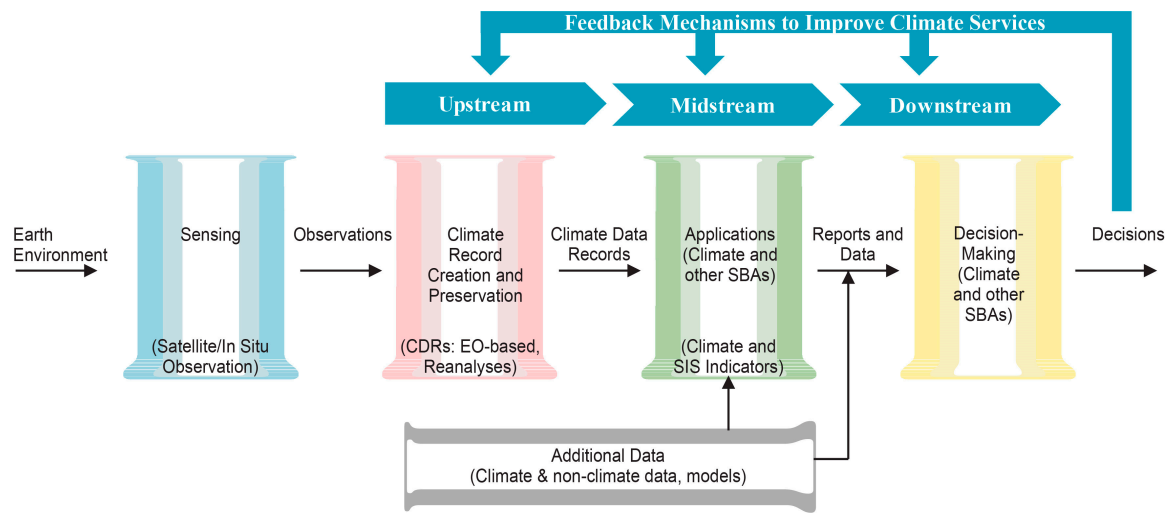

Figure 4. Use cases description following a common template, indicating when facilitated with additional data (e.g., climate \& non-climate data, models), the use case description can provide a practical demonstration of the logical structure of the Architecture for Climate Monitoring from Space (AMCS) in terms of its functions, information flows, and dependencies. The upstream, midstream and downstream segments of climate services for a typical use case was mapped correspondingly atop the climate data and information flow. (CDRs-Climate Data Records; EO-Earth Observation; SBAs-Societal Beneficial Areas; SIS-Sectoral Information System).

The above use case description will help end-users understand the value of climate services that are based on ECV products, as well as follow the product user guidance (PUG). The high-level qualitative user guidance on the use of each product or combination of products shall contain [59]: definition of the data set; requirements considered while developing the data set; overview of input data and methods; general quality remarks; validation methods and estimated uncertainty in the data; strength and weakness of the data; format and content description; references and contact details. 
As such, a PUG will describe to a user the instructions required on how to use the particular ECV data products, via synthesizing the contents above. These contents can be subsequently and readily accessed from the multi-product inventory.

The PUG should enable certain indicators reflecting the readiness of the ECV for specific applications. Such indicators shall facilitate the comparison of the real technical features of a data record and results of validations against user requirements for a particular application. The prototyped Application Performance Matrix (APM), developed in CORE-CLIMAX, can serve as the readiness indicator of the ECV product for the application considered [57]. The need for APM is manifested, for instance, in the vast amount of information provided on the validation of data records that is unlikely to be processed by institutions that want to use the data records. The APM is intended to support institutions in making choices among different existing data records without the need to assess the full documentation of all potential data records.

To be able to apply the APM, user requirements for each application shall be compared against the actual technical specifications and validation results. The APM provides summary information on how close a specific data record is at fulfilling the requirements of a specific application. The following demonstrates an exemplary use of APM to address the policy-maker question on: Are there trends in North Sea Temperature over the last 15 years that could affect fisheries? The policy-maker question was further translated to APM as: Which data records are suited to analyze trends in this rather small region? The next step is to link the question toward APM with the specific user requirements, considering three levels of quality targets for ECV products, namely: threshold, breakthrough and optimum. This step will enable a user requirement table to be constructed, against the actual technical specifications of relevant ECV products in the climate data inventory. The assessment result from this step will deliver APM scores as presented in Table 2 for the current use case [60].

Table 2. Example of Application Performance Matrix (APM) scores for addressing the policymaker question on: Are there trends in North Sea Temperature over the last 15 years that could affect fisheries? Two datasets (HadISST1 and $\mathrm{CCl}$ Analyses) provide the CDR requested for this specific application. User requirements (Coverage, Temporal Resolution, etc.) are specified in three levels, 1-target (amber), 2-breakthrough (light green), 3-optimum (dark green), while 0 indicates "Not Acceptable". Colors and numbers indicate up to which level user requirements are satisfied. $\left({ }^{*}=\right.$ treat with cautions).

\begin{tabular}{ccccccc}
\hline CDR Name & Coverage & $\begin{array}{c}\text { Temporal } \\
\text { Resolution }\end{array}$ & $\begin{array}{c}\text { Horizontal } \\
\text { Resolution }\end{array}$ & $\begin{array}{c}\text { Vertical } \\
\text { Resolution }\end{array}$ & $\begin{array}{c}\text { Length of } \\
\text { Record }\end{array}$ & $\begin{array}{c}\text { Stability } \\
\text { (K/decade) }\end{array}$ \\
\hline HADISST1 & 3 & 1 & 1 & 1 & 3 & $3^{*}$ \\
\hline CCI Analysis & 3 & 3 & 2 & 1 & 0 & $3^{*}$ \\
\hline
\end{tabular}

\section{Thematic Assessments}

The advent of climate services will bring greater demands on the breadth and depth of product inter-comparison activities. While the original ECVs were designed mainly on the basis of individual usefulness, recent efforts have started to use the CDR of ECVs to close budgets of energy, carbon and water cycles, and to study interactions between land, atmosphere, and ocean in a more integrated way $[49,50]$. In particular, GCOS IP 2016 sets out the quantitative targets on closing the budgets of these climate cycles [38]. The examination of the budgets of these cycles will allow us to identify scientific gaps in the fundamental understanding of the natural processes. As such, this understanding will subsequently support improved forecasts of the impacts of climate change. The thematic assessment is to document the physical consistency of multiple ECV products, and thus to evaluate the budgets of the climate cycles.

The specific aim(s) of thematic assessment can involve, and is not limited to, the overarching questions such as: What are the relevant natural processes represented by the ECV products for the thematic assessment? Are the ECV products consistent with each other to enable the natural process representation? What are the limitations of the ECV products for representing the natural process? Are the ECV products consistent with model data so that modeled and observation data can be used directly for model validation and data assimilation? 
Before the implementation of thematic assessment, the overview of "ECV product characteristics" (i.e., from multi-product inventory) and "ValQI (Scientific Integrity)" will provide a descriptive comparison of the ECV products for the assessment (see Table 3 for an example). The characteristic description will provide the first level of information to understand, for example: "Are the ECV products using the common source of background data or not? Are they consistent when spatiotemporally averaged to the same scales? Are they meeting the GCOS requirements?" Furthermore, the ValQI will enable readiness for the scientific integrity of ECV products. Such basic information will facilitate the meaningful interpretation of the assessment results, and will inevitably help users to understand better the thematic assessment results.

Table 3. Example of the overview of thematic ECV products to provide first level information on "ECV product Characteristics" and "Maturity of Products (Scientific Integrity)." (Note: The ECV product characteristics are from the procurement document of C3S [61-63], while the maturity scores are from ESA CCI products as evaluated in the CORE-CLIMAX ECV CDRs capacity assessment report [57]). (SIC-Sea Ice Concentration, SIE-Sea Ice Extent, SIT-Sea Ice Thickness; SST-Sea Surface Temperature; 'means this cell needs further inputs, or currently not defined by end-users).

\begin{tabular}{|c|c|c|c|c|c|c|}
\hline & \multicolumn{2}{|c|}{ ECV } & \multicolumn{3}{|c|}{ Sea-Ice } & $\begin{array}{l}\text { Sea-Surface } \\
\text { Temperature }\end{array}$ \\
\hline & \multicolumn{2}{|c|}{ Product Acronym } & SIC & SIE & SIT & SST \\
\hline & \multicolumn{2}{|c|}{ Type of Product } & Satellite & Satellite & Satellite & Satellite \\
\hline & \multicolumn{2}{|c|}{ Sources } & C3S_312 & C3S_312 & C3S_312 & C3S_313 \\
\hline & \multicolumn{2}{|c|}{ Observation Inputs } & Multi-Sat & Multi-Sat & Multi-Sat & Multi-Sat \\
\hline 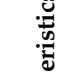 & \multicolumn{2}{|c|}{ Ancillary Data } & $\begin{array}{c}\text { ECMWF } \\
\text { Land-sea masks }\end{array}$ & $\begin{array}{c}\text { ECMWF } \\
\text { Land-sea masks }\end{array}$ & $\begin{array}{c}\text { ECMWF } \\
\text { Land-sea masks }\end{array}$ & $\begin{array}{c}\text { ECMWF } \\
\text { Land-sea masks }\end{array}$ \\
\hline 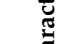 & \multicolumn{2}{|c|}{ Geographic Domain } & Global & Global & Global & Global \\
\hline 己ี่ & \multicolumn{2}{|c|}{ Time Range } & - & - & - & - \\
\hline 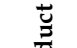 & \multirow{2}{*}{ Res. Horizontal } & Current & - & - & - & - \\
\hline I & & GCOS & $10-15 \mathrm{~km}$ & $1-5 \mathrm{~km}$ & $25 \mathrm{~km}$ & $10 \mathrm{~km}$ \\
\hline$\vec{u}$ & \multirow{2}{*}{ Res. Vertical } & Current & - & - & - & - \\
\hline & & GCOS & - & - & - & - \\
\hline & \multirow{2}{*}{ Res. Temporal } & Current & - & - & - & - \\
\hline & & GCOS & weekly & weekly & weekly & daily \\
\hline & \multirow{2}{*}{ Accuracy } & Current & - & - & - & - \\
\hline & & GCOS & $5 \%$ & $5 \mathrm{~km}$ & $0.1 \mathrm{~m}$ & $0.1 \mathrm{~K}$ \\
\hline & \multirow{2}{*}{ Stability } & Current & - & - & - & - \\
\hline & & GCOS & $5 \%$ & - & - & $0 . .03 \mathrm{~K} /$ decade \\
\hline \multirow{10}{*}{ 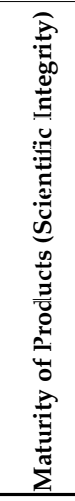 } & \multicolumn{6}{|c|}{ User Documentation } \\
\hline & \multicolumn{2}{|c|}{$\begin{array}{l}\text { Formal description of scientific } \\
\text { methodology }\end{array}$} & 3 & - & - & 2 \\
\hline & \multicolumn{2}{|c|}{ Formal validation report } & 3 & - & - & 3 \\
\hline & \multicolumn{2}{|c|}{ Formal product user guide } & 4 & - & - & 5 \\
\hline & \multicolumn{2}{|c|}{$\begin{array}{c}\text { Formal description of operations } \\
\text { concept }\end{array}$} & 3 & - & - & 4 \\
\hline & \multicolumn{6}{|c|}{ Uncertainty Characterization } \\
\hline & \multicolumn{2}{|c|}{ Standards } & 3 & - & - & 4 \\
\hline & \multicolumn{2}{|c|}{ Validation } & 4 & - & - & 4 \\
\hline & \multicolumn{2}{|c|}{ Uncertainty quantification } & 4 & - & - & 5 \\
\hline & \multicolumn{2}{|c|}{ Automated quality monitoring } & 3 & - & - & 4 \\
\hline \multicolumn{7}{|c|}{ Maturity Scores: } \\
\hline \multicolumn{2}{|c|}{12} & 3 & 4 & 5 & 6 & \\
\hline \multicolumn{2}{|c|}{$\begin{array}{c}\text { Research Capability } \\
\text { (RC) }\end{array}$} & \multicolumn{2}{|c|}{$\begin{array}{c}\text { Initial Operations Capability } \\
\text { (IOC) }\end{array}$} & \multicolumn{2}{|c|}{$\begin{array}{l}\text { Full Operations Capability } \\
\text { (FOC) }\end{array}$} & \\
\hline
\end{tabular}




\section{Usability Assessment}

The usability assessment is to evaluate the usability and to develop guidance on fitness-for-purpose of specific ECV products for their use cases. With the preceding assessments, information is produced regarding the quality of delivered ECV products, including information on the observation basis of the original products and its post-processing steps. Together, these should provide essential meta-information on datasets to inform potential users and enable the comparison of datasets, to evaluate the fitness for purpose (F4P) for the envisaged use cases.

Output oriented quality assessment can only be operationalized in a meaningful way if there are links between quality features of the output and the resulting benefit (utility) for the user(s) of the climate services. As such, the contribution of usability assessment is also to detail what the essential metadata is for the end-user, and to understand how the prospective end-user can benefit from the metadata. Furthermore, given these insights, the end-user will provide feedbacks to climate service providers on the presentation and validation of metadata. The use case can describe the value chain from ECVs, through tailored information in local workflows to sector decision-making process (see Figure 5), which is a "drilling-down" (i.e., more details) of Figure 4 from midstream to downstream.

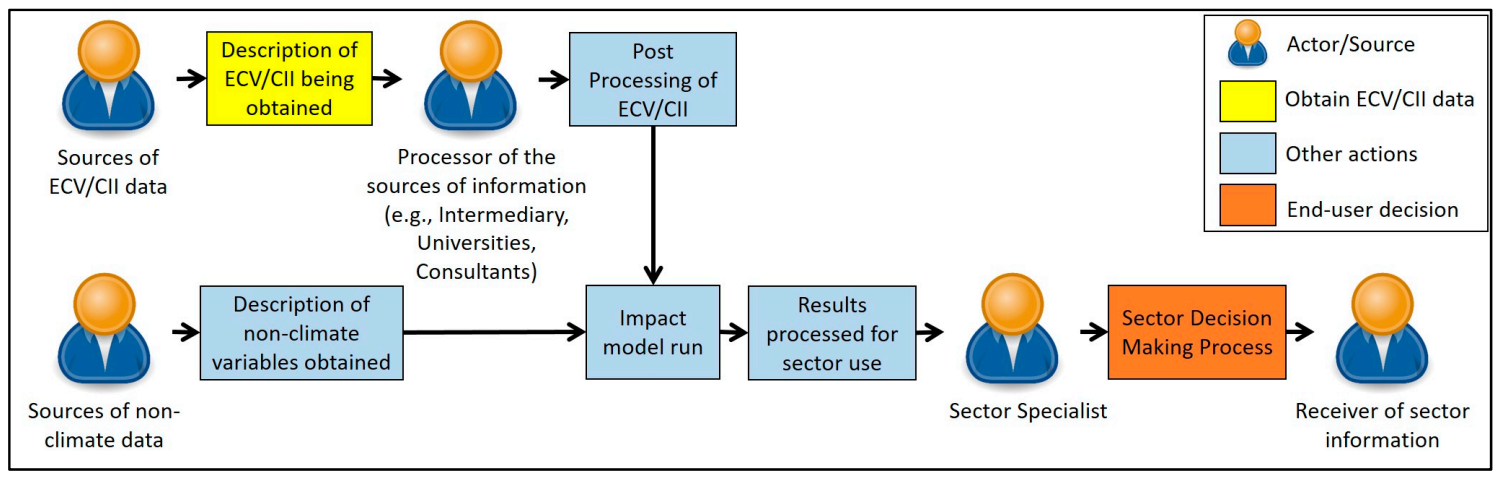

Figure 5. Basic use case diagram example. ( $\mathrm{CII}=$ Climate Impact Indicator).

Details of the use case include specifying the sector, end user and problem that the user is trying to solve. To detail how uncertainty affects a decision, one will need to simulate how uncertainty properties of delivered series (e.g., climate impact indicators) affect sector decision making, according to the resulting benefits. Based on the quantitative uncertainty of the ECV products, the simulation can be made for a specific sector decision making process and receiver of sector information. Where possible, the results of the simulation need to be discussed with the end-user, and feedback collected to be incorporated into follow-up use cases and overall evaluation of usage information. In the following sub-sections, a reinsurance case study on extreme El Niño events was used to demonstrate the usability assessment.

\subsection{Detail Use Case and User Requirements}

The first step is to detail the use case, specifying the sector, end-user and the problem that the user is trying to solve. The user requirement details can be pre-collected from existing consolidated requirements on the quality information for the specific sector, and then further updated with the end-user interview. Table 4 provides the details of the use case for an insurance company in Peru, who requested to quote on a suggested insurance product that would protect them from extreme El Niño events [64].

To quantify the severity of EI Niño events, the Niño $1+2$ index was chosen, due to its geographical proximity to Peru, this index has a more direct impact on Peru compared to other El Niño indices (see Figure 6a). The Niño 1+2 values refer to the November-December average of sea surface temperatures in $\left(90-80^{\circ} \mathrm{W}, 0^{\circ}-10^{\circ} \mathrm{S}\right)$. The idea of this insurance product is that when Niño $1+2$ exceeds a certain threshold (i.e., entry point), the client receives some payout till reaching a maximum at a higher Niño 
$1+2$ value (i.e., exit point). Payout begins at zero for the entry point Niño $1+2$ of $24^{\circ} \mathrm{C}$ and increases linearly to the maximum payout (let us assume $50 \mathrm{M}$ USD) for the exit point Niño $1+2$ of $27^{\circ} \mathrm{C}$.

Table 4. An example of detailing use case and user requirements for an insurance company.

\begin{tabular}{|c|c|}
\hline \multicolumn{2}{|r|}{ Detail Use Case } \\
\hline Sector & Disaster Risk \\
\hline End user & Insurance company \\
\hline $\begin{array}{l}\text { Problem at hand that the } \\
\text { user is trying to solve: }\end{array}$ & $\begin{array}{l}\text { El Nino conditions can affect severely the economy and infrastructure. In } 1997 \text { an } \\
\text { extreme El Nino event caused multiple problems. To bring some examples, } \\
\text { anchovy production (an important economic activity in Peru) was reduced } \\
\text { because elevated sea temperatures off the Peruvian coasts reduced spawning and } \\
\text { forced the fish population to migrate elsewhere. Agricultural yields on land } \\
\text { decreased dramatically as a result of extreme precipitation. Further consequences } \\
\text { of extreme precipitation were floods and landslides that destroyed private } \\
\text { property and public infrastructure such as roads and bridges. Damage in public } \\
\text { infrastructure in turn affected transportation and electricity } \\
\text { production/distribution leading to further economic losses. Financial institutions } \\
\text { such as banks were also affected since the disruptions in economic activity forced } \\
\text { many businesses and private borrowers to suspend loan payments. As a result, } \\
\text { insurance losses from various lines of business were particularly large. Insurance } \\
\text { companies request to quote on a suggested insurance product that would protect } \\
\text { them from extreme El Nino events. }\end{array}$ \\
\hline \multicolumn{2}{|r|}{ Detail user requirements } \\
\hline User requirement collection & Directly engaging end-users for their needs. \\
\hline Verification & Envolving end-users to co-develop the insurance product \\
\hline
\end{tabular}

\subsection{Detail How Uncertainty Affects Decisions}

\subsubsection{Extreme EI Niño Event: What Is the Price?}

Most El Niño-related disruptions in Peru start around January, but the associated elevated sea surface temperatures in the Pacific are already occurring in November-December. The November-December Niño 1+2 value is known the beginning of January each year. This allows the client to receive payout in January when losses start occurring [65].

(a)

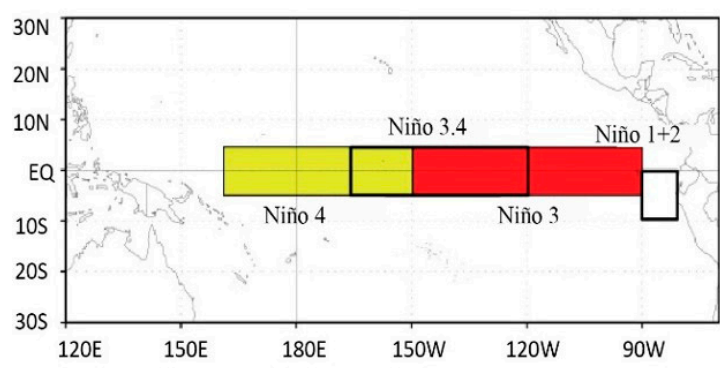

(b)

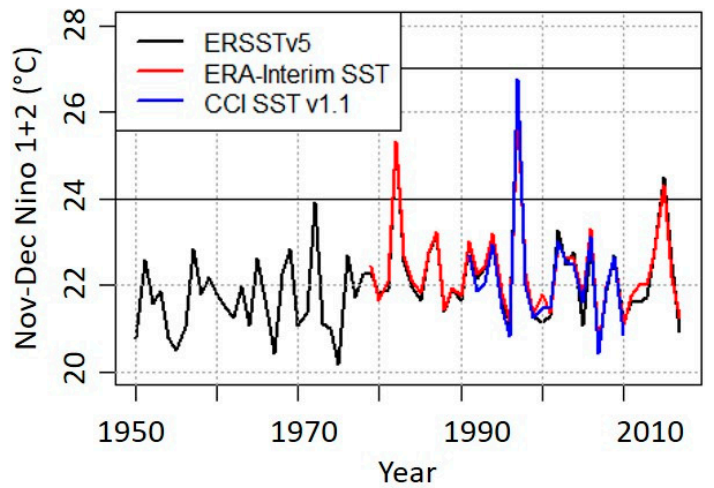

Figure 6. (a) The outline of regions used for assorted Niño indices [66], indicating that Niño 1+2 index is the most relevant for the area of Peru; (b) Time series of the ERSSTv5, ERA-Interim SST and ESA-CCI SST v1.1 Niño $1+2$ index.

The aim of the following exercise is to choose appropriate historical values of the Niño $1+2$ index and use them to estimate an annual average payout. Three alternative sources of gridded data were used for the required Niño 1+2 values. These are the Extended Reconstructed Sea Surface Temperature 
Version 5 [67], the ERA-Interim reanalysis [68] and the ESA Sea Surface Temperature Climate Change Initiative (ESA SST CCI) Analysis long term product version 1.1 [69]. Figure $6 \mathrm{~b}$ and Table 5 provides an overview of the three datasets.

Table 5. Data used for the pricing of the insurance product.

\begin{tabular}{cccccc}
\hline Products & Institutions & $\begin{array}{c}\text { Type of } \\
\text { Dataset }\end{array}$ & Time Span & $\begin{array}{c}\text { Time } \\
\text { Resolution }\end{array}$ & $\begin{array}{c}\text { Spatial } \\
\text { Resolution }\end{array}$ \\
\hline $\begin{array}{c}\text { ERA-Interim } \\
\text { SST }\end{array}$ & ECMWF & reanalysis & $1979-2017$ & $6 \mathrm{~h}$ & $\begin{array}{c}\text { approximately } \\
80 \mathrm{~km}\end{array}$ \\
\hline ERSSTv5 & NOAA & $\begin{array}{c}\text { mostly in-situ } \\
\text { observations }\end{array}$ & $1950-2017$ & monthly & $2^{\circ}$ \\
\hline CCI SST v1.1 & ESA & $\begin{array}{c}\text { satellite } \\
\text { observations }\end{array}$ & $1991-2010$ & daily & $0.05^{\circ}$ \\
\hline
\end{tabular}

For the pricing of the insurance product, the frequency and severity of potential payouts must be calculated. One way to do this is to calculate the losses for the historical events, where Niño 1+2 exceeded the $24{ }^{\circ} \mathrm{C}$ threshold. Based on the ERSSTv5 data, there are three such events in 1982, in 1997 and 2015 (Figure 6b). The 1997 and 2015 events also appear in the other two datasets. The average annual loss calculated from the historical ERSSTv5 data is 1.1 million USD. Using the full length of the ERSSTv5 time series for the calculation of historical losses makes the comparison with CCI SST time series difficult because CCI SST covers a shorter time (1991-2010). Therefore, for ERSSTv5 and ERA-Interim data the average annual loss calculations were carried out for the full available period and the period 1991-2010 (Table 6).

Table 6. Average annual loss in million (USD) using the three different datasets and different time periods.

\begin{tabular}{cccc}
\hline Calculated Periods & ERSSTv5 & ERA-Interim & CCI SST \\
\hline historical full length & 1.1 million USD & 1.6 million USD & 2.3 million USD \\
\hline historical 1991-2010 & 2.2 million USD & 1.8 million USD & 2.3 million USD \\
\hline GEV full length & 0.7 million USD & 1.0 million USD & 1.4 million USD \\
\hline GEV 1991-2010 & 1.6 million USD & 1.2 million USD & 1.4 million USD \\
\hline
\end{tabular}

As an alternative approach to calculating average annual losses, a probability distribution function (namely the Generalized Extreme Value, GEV family of distributions) is fitted to all three datasets using maximum likelihood [70]. The GEV distribution is the limit distribution of normalized maxima of a sequence of independent and identically distributed random variables. The GEV distribution tends to have large probability density for extreme values. This means that under a GEV assumption, extreme losses are relatively frequent, when compared to a normal distribution. The GEV distribution is a suitable (although not unique) choice for this example, because it is important not to underestimate the frequency and severity of extreme events. The same distribution has been fitted to all data using the same statistical software [71,72] to ensure consistency.

To facilitate comparison among the three datasets, the GEV has been fitted to the full ERSSTv5 and ERA-Interim data as well as to the subsets covering the period 1991-2010 only. Figure 7d shows the exceedance probability function of the GEV distribution fitted to the full ERSSTv5 dataset. Table 6 shows the annual average loss using the GEV distribution fitted to the full datasets and the data corresponding to the period 1991-2010. Plots a, b, and c of Figure 7 compare observed and modeled temperatures for the same quantiles. For temperatures up to approximately $23{ }^{\circ} \mathrm{C}$, there is a good match. For temperatures in the range $23^{\circ} \mathrm{C}-24^{\circ} \mathrm{C}$, modelled temperatures tend to be higher. While for temperatures above $24^{\circ} \mathrm{C}$, modelled temperatures tend to be lower. The comparison between 
observed and modeled temperatures is particularly difficult for very high temperatures, because sample quantiles of extreme values tend to have large biases [73].
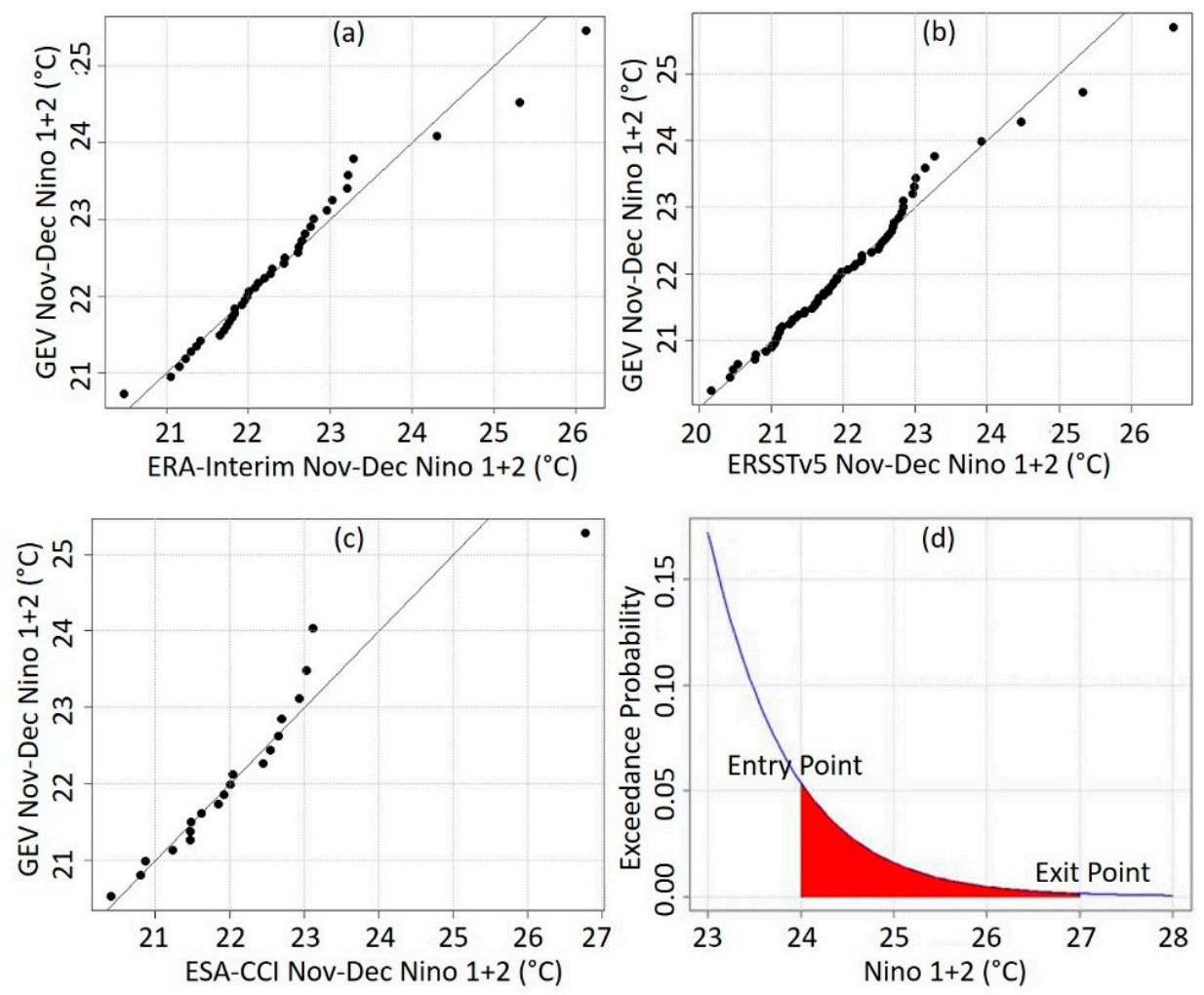

Figure 7. QQ (quantile-quantile) plot for assessing goodness of fit of the GEV distribution (the full-length data have been used here). The corresponding datasets are: (a) ERA Interim SST; (b) ERSSTv5; (c) ESA CCI SST. And, (d) the exceedance probability function (also known as complementary cumulative distribution function), demonstrating the probability that Niño1+2 greater than or equal to $24{ }^{\circ} \mathrm{C}$ is 0.053 (=return period 19 years).

The historical annual average loss tends to decrease for more extended datasets (Table 6). The ERSSTv5 has the lowest annual average loss, which is attributed to the long averaging period of 68 years. If we take the period 1991-2010, the differences between the three datasets are smaller but still considerable. The annual average loss based on the GEV model also tends to decrease with increasing averaging period, and it is smaller than the losses calculated from the historical data. An interpretation of the results of the GEV model is that in the long run, less severe El Niño events are expected compared to the El Niño events observed in the recent observation records. It is notable that the GEV model choice is not unique, and it may be possible to fit another distribution function, which would give results closer to the observations.

\subsubsection{What Causes the Difference? Which Is the Most Suitable Dataset?}

The fact that we get different results using different datasets begs the question: Why are there differences and which dataset is the most suitable? Differences between datasets could be attributed to data uncertainty, or there could be known biases. Both these aspects should be communicated to the end user to help choose a dataset. In this particular application, we are mostly concerned with uncertainty and biases for extreme events.

A further important criterion for the selection of data in addition to accuracy is the length of the available data records. This is because extreme events are rare by definition and therefore a sufficiently long record is required to estimate statistics such as the expected payout frequency and the annual 
average payout. In other words, a somewhat less accurate but very long dataset may be preferred over a shorter and more accurate one. Details on the uncertainty of the candidate datasets can help reach a decision here as well.

An aspect to consider, especially when it comes to longer data records, is data homogeneity. In the curve fitting process presented above it has been assumed that the statistical properties of all three time series do not change with time. In the time series shown in Figure $6 \mathrm{~b}$ all three payouts occur after 1980. This could happen because of chance, it could represent climate change affecting the frequency and severity of El Niño events, or it could represent a data homogeneity issue. Examples of data inhomogeneity include changes in instrumentation or changes in the quality and amount of observations included in data assimilation of reanalysis products [74]. The data provider can help the data user by providing details on possible data inhomogeneity problems, steps that were taken to resolve them and possible remaining issues. As such, the difference in the average annual loss can be traced back to these different steps used for harmonizing data, which can be further attributed to the uncertainty of data in the upstream of climate services.

\section{Discussion and Conclusions}

\subsection{Limitations}

\subsubsection{Traceability of In-Situ-Based CDRs}

The space branch of quality assurance procedures and framework has been developing and maturing $[8,22,29,35,54,75,76]$. The generic logical view can identify the structured process for CDR production from space (i.e., from raw measurements to CDR archive), which represents the interlinked functions and associated data-flow meeting the various climate monitoring requirements [41]. The structured process subsequently enables a potential, thorough uncertainty analysis of the whole CDR production chain. Each component of the CDR production chain should be associated with a step of uncertainty analysis. When the uncertainty analysis reaches the last part of the production chain, the law of propagation of uncertainty should be applied to understand the overall uncertainty of CDR products [77-79], which contain all quantities that contribute to the uncertainty of the final CDR products [80,81]. As such, the quality assessment of CDR investigates not merely the physical law associated with the measurement but also the entire production chain of CDRs.

However, there is currently no internationally recognized quality assurance framework for in-situ based ECV CDRs. The CORE-CLIMAX European ECV CDR Capacity Assessment Workshop demonstrated that the quality aspects of in-situ based ECVs cannot be systematically addressed by the CORE-CLIMAX System Maturity Matrix [11,57]. Such mismatch is mainly caused by the lack of a generic logical view (e.g., on the functions and information flows) to produce CDR from in-situ data. There are at least two primary barriers to derive a generic logic view for in-situ based ECV CDR production:

(1) The historically heterogeneous governance structures of in-situ observation networks have inevitably led to significant difference in data policy, adoption of network nomenclatures and practices. The consequence of this heterogeneity places end users in a dilemma to understand the measurement systems and networks, on an ECV-by-ECV basis, while not likely having the time and/or the necessary in-depth knowledge and expertise to achieve a full understanding [54,82,83];

(2) The lack of a commonly adopted system-of-systems approach to enhance linkages between the different components of the climate observing system, such as infrastructure co-location, inter-comparison campaigns, information sharing, training and development $[27,83]$.

The first barrier has been well recognized [82], and there are currently efforts towards the removal of the barrier. The pioneering examples (i.e., not in a holistic way) are GRUAN (GCOS Reference Upper-Air Network) [84,85], ICA\&D (International Climate Assessment and Dataset) [34] and USCRN (U.S. Climate Reference Network) [79,86,87]. The endeavor to approach the second barrier is only 
recently made within the GAIA-CLIM project [83], wherein the Measurement System Maturity Matrix (MSMM) was proposed to be adapted to serve the purpose of system-of-systems approach, based upon the substantial work undertaken by CORE-CLIMAX [11] and a number of precursor studies assessing dataset maturity [88].

Given the experience for the space-based ECV CDR production, with the generic logical view developed jointly by CEOS, CGMS and WMO [29], it is envisioned that a comprehensive, logical view for in-situ based CDR production with compatibility to the space-based one is within reach. Particularly, the logical structure of the Architecture for Climate Monitoring from Space (ACMS) can be used as a "template" to map the description of the use case, enabling the practical demonstration of ACMS. There are ongoing efforts on addressing the incorporation of independently coordinated in-situ observation networks into the ACMS, ultimately yielding a description of the functional components of an integrated, in-situ and space-based climate monitoring system [29,79,83,89].

\subsubsection{Traceability of Earth System Reanalysis}

Reanalysis of the Earth system typically covers several elements. For example, the recent reanalysis from NCEP [90] covers atmosphere, land, ocean (surface and sub-surface), and sea-ice. The current ECMWF reanalysis [68] covers atmosphere, ocean surface (waves), and land. For the sake of the present discussion, an Earth system element is said to be covered if:

(1) It is represented by a model which attempts to reproduce variations from known physical laws or parameterizations (e.g., for sea-ice: a sea-ice model);

(2) The states produced by such model are updated for one or several geophysical variables by assimilating observations of this Earth system element. For example, for ocean waves, satellite altimeter wave-height observations can be assimilated to update ocean current and biogeochemical variables.

As all ECVs produced by a reanalysis are the products of a single reanalysis system, the system validation (to enable traceable quality information) is necessary [74,91,92]. Models of the various elements can be as far as coupled or fully integrated, but there are still generally strong disconnections between the various Earth system elements in the assimilation. For example, analysis updates from either satellite or in-situ observations (so-called increments) are typically computed separately for each Earth system element data assimilation, and it is only during the model integration that all states are made physically consistent between one another. This point has consequences for tracing uncertainties through the reanalysis production chain, as it entails also considering the validation of each ECV produced separately.

The processes involved in reanalysis production are validated by monitoring several metrics. For an assimilation system, these involve the following components: (1) the observations input; (2) the forcing or boundary datasets input; (3) the model configuration (for the various Earth system elements); (4) the data assimilation system (in the various Earth system elements). For all of the above, the reanalysis producers generally rely on reports and published papers to make choices regarding maturity and reliability and to decide whether the component selected is suitable for their application. It is notable that a reanalysis production covers several years or decades of product periods and may take months or years to complete. Once this "input checking" has been done, all reanalysis components are validated during production as follows.

The forcing or boundary datasets input is validated by generating time-series of the mean state (averaged across some spatiotemporal domain) and its deviations (time increments and standard deviations within the spatiotemporal grid). In the case of ensemble datasets, the variations in ensemble spread are compared against expectations (e.g., expecting lower spread in areas of lower natural variability and greater sampling).

The observations input is validated by sub-setting the various observation types and variables and plotting their general characteristics, using some forms of averaging to reduce the amount of 
information to a few selected granules. An important validation is to verify that the input is as expected, i.e., by inspecting timelines of observation sources. The producers validate that the observations get used as expected. For example, the producers can check the number of observations in total, identify how many observations are accepted or rejected, and separate reasons to identify potential problems [93,94].

As a reanalysis production can last months or years and be ported across several computing environments, the model configuration is checked for unwanted changes. This validation usually happens at regular intervals during the lifetime of a reanalysis production, by comparing the production logs with a reference log (such as one produced in the early stages of production). The behavior of the model itself is usually validated by running a long model integration without assimilation (similar to so-called AMIP integrations [95]), and inspecting the climate trends produced, as well as global energy and water budgets.

The data assimilation system is validated by inspecting the primary metrics such as, for a variational system, the observational cost function, its reduction during the analysis minimization, and validating them against expectations. All quantities produced by the assimilation system are monitored, such as analysis increments, reduction in the distance to assimilated observations, observation bias corrections, background errors (i.e., due to model structure or relevant physical parameterizations) when dynamically updated, and reduction in ensemble spread caused by the analysis in the case of ensemble productions [94]. In that respect, an important validation is the comparison between assumed (background and observation) errors and effectively observed background departures in the system, using the observations as a non-perfect reference (taking into account its errors). The ECV CDRs produced by a reanalysis system are then compared against independent reference datasets. Validation is also conducted by cross-referencing departures before and after assimilation for the assimilated observations. Furthermore, important conclusions about the relative biases in the various observations can be retrieved from such detective work [96].

From the above, it is evident that the characterization of reanalysis uncertainties (to be traceable) is complicated. To assist users in deciding which reanalysis product might be most suitable for their particular application, CORE-CLIMAX project has proposed [11]: (1) procedures for feeding back improved reanalysis-based ancillary data to assist CDR updates [97]; (2) support infrastructure for CDR quality assessment in a reanalysis environment [98]; (3) procedures for feeding back reanalysis results and plans to CDR producers at two levels (i.e., peer-to-peer level, and the synthesis level) [99]; (4) a process to intercompare reanalysis [58,100].

To realize the above proposals, one needs to build the underlying technical solutions (i.e., design and implementation of suitable databases and tools), the progress of which will be reflected by maturity ratings of the CORE-CLIMAX System Maturity Matrix. There are ongoing international programs and initiatives with mechanisms addressing the above needs, but further work is required to establish consolidated best practices and improve coordination within and between such activities $[35,101,102]$.

\subsection{Conclusions and Outlooks}

The ECV concept [33], the architecture for climate monitoring from space [29] and the construction of ECV inventory [46] enable the synthesized overarching structure for the assessment of quality and usability of ECV products (AQUE). The AQUE aims to ensure that end-users of climate services have access to the quality-assured data about the monitored climate, together with clear contextual guidance on the use of these data and the resulting benefit (utility) for the users. The AQUE is fundamental to ensuring the climate data and information are consistent and to establishing the relation of trust between climate information providers and various downstream users. The trust relation, if established, will foster the sustainable use of climate data and derived information products leading to a flourishing market for climate services.

The overarching AQUE structure provides a logical flow for the quality assurance of single-products, multi-products, and thematic products, as well as their usability assessments. It is to 
note that various end-users can have different application scenarios of AQUE structure, and do not necessarily start sequentially from single-product, going through multi- and thematic-products, and end at usability assessment. Depending on the particular application and the availability of ECV CDRs, end-users can start from any box of climate data product as suggested by the Application Performance Matrix (APM), provided with fully characterized uncertainty information. The basic principle of APM is to evaluate how well the data records' technical specifications and accessible validation results can match the user requirements for the application desired. As such, the APM is bridging the identified user requirements with the product specifications that are available in the Climate Data Inventory (CDI) or ECV inventory.

To perform a usability assessment, it is essential to detail the use case and user requirement. Preferably, the latter should be verified and validated with end-users in a participatory manner. However, the specific user requirement can also come from existing user requirement database (URDB) [13], emanating from a wide variety of user fora, surveys, and support panels. This URDB is the most useful for those end-users not familiar with climate data and information products, and not comprehending how to identify user requirements. Once the user requirement on climate data and information products are identified and verified, the search in the CDI will be performed and provide inputs for the APM to create a traffic-light type of priority ranking for the recommended matched CDRs. Those ECV CDRs with green lights will be further evaluated on how uncertainty will affect the sector decision-making process (i.e., via resulting benefits), as demonstrated with the reinsurance example of Extreme EI Niño events.

The current international context contains a number of programs and initiatives focusing on developing technical solutions underlying different components of the AQUE overarching structure. For example, the Evaluation and Quality Control (EQC) function of C3S has focused on the quality assurance of single-products, multi-products and thematic products [12-14], as well as the quality assurance of the sectoral information system (i.e., quality assurance of climate services) $[15,16]$. The joint CEOS /CGMS Working Group on Climate (WGClimate) has coordinated space agencies to implement the Architecture for Climate Monitoring from Space (ACMS) via establishing the ECV Inventory, developing case studies and collecting observation needs. The European Space Agency (ESA) Sensor Performance, Products and Algorithms (SPPA) team has managed a series of "Fiducial Reference Measurements" (FRM) projects, targeting the validation of ESA products following the QA4EO guidelines. GCOS and WMO develop the observing system capability analysis and review tool (OSCAR), to publish and regularly review the quality requirements of satellite-derived ECVs, against the climate monitoring needs of the UNFCCC, IPCC and WMO programs. GEOSS has developed the GEOSS Platform (formerly the GEOSS Common Infrastructure - GCI), which aims to provide a shared, easily accessible, timely, sustained stream of comprehensive data of documented quality, as well as metadata and information products, for informed decision-making.

There are many more programs and initiatives with the context of quality assurance of ECV CDRs from space, when looking at the international and European landscape of climate services [4,26]. Nevertheless, there is not yet a consistent, international coordination mechanism for in-situ observations and reanalysis for climate services $[11,29,35,54,83,89,103,104]$. It is evident that the upstream of climate services has been developing and maturing, while the midstream and downstream are still in their infancy $[105,106]$. To assist climate services moving towards a demand-driven and science-informed approach, and therefore moving faster towards midstream and downstream, the usability assessment is a stepping-stone. The usability assessment of AQUE structure contributes to enhancing trust in climate services, addressing the efficacy of communication strategies and uncertainty communication. As such, AQUE can serve as inputs to share quality information between communities and to collect lessons learned that could be potentially turned into evolving best practices for climate services.

Author Contributions: Conceptualization, Y.Z. and Z.S.; methodology, all; writing-original draft preparation, Y.Z., Z.S., I.B., A.P., P.P., V.O.J., R.R., J.S., and X.M.; writing-review and editing, Y.Z., Z.S., K.F.B., W.T., A.F., K.d.B., H.G., V.J., R.R. and J.S.; visualization, Y.Z.; supervision, Z.S.; project administration: W.T., funding acquisition, Z.S. 
Funding: This research received partial funding from CORE-CLIMAX project, financially supported by the European Union within the Copernicus initiative in its Seventh Framework Programme (FP7 Grant Agreement 313085).

Acknowledgments: We acknowledged three anonymous reviewers' comments for improving the presentation of our manuscript.

Conflicts of Interest: The authors declare no conflict of interest.

\section{Appendix A. Key Acronyms Used in this Paper}

\begin{tabular}{|c|c|}
\hline 20CRv2 & $20^{\text {th }}$ Century Reanalysis \\
\hline 3DVAR & Three-dimensional variational data assimilation \\
\hline 4DVAR & Four-dimensional variational data assimilation \\
\hline ACMS & Architecture for Climate Monitoring from Space \\
\hline AMIPS & Atmospheric Model Inter-comparison Project \\
\hline AMSU & Advanced Microwave Sounding Units \\
\hline $\mathrm{APM}$ & Application Performance Matrix \\
\hline AQUE & Assessment of the Quality and Usability of ECV Products \\
\hline C3S & Copernicus Climate Change Service \\
\hline CDR & Climate Data Record \\
\hline CDI & Climate Data Inventory \\
\hline CEOS & Committee on Earth Observation Satellites \\
\hline CGMS & Coordination Group for Meteorological Satellites \\
\hline CIRES & Cooperative Institute for Research in Environmental Sciences \\
\hline CNES & Centre National d'Etudes Spatiales \\
\hline CORE-CLIMAX & Coordinating Earth observation data validation for RE-analysis for CLIMAte ServiceS \\
\hline ECMWF & European Centre for Medium-Range Weather Forecasts \\
\hline EQC & Evaluation and Quality Control \\
\hline ERA-Interim & ECMWF Reanalysis Interim \\
\hline ERA-20C & ECMWF Twentieth Century Reanalysis \\
\hline ERSSTv5 & Extended Reconstructed Sea Surface Temperature Version 5 \\
\hline ESA & European Space Agency \\
\hline ESA-CCI & ESA Climate Change Initiative Project \\
\hline F4P & Fitness-for-Purpose \\
\hline FCDR & Fundamental Climate Data Record \\
\hline FIDUCEO & Fidelity and uncertainty in climate data records from Earth Observations \\
\hline GAIA-CLIM & Gap Analysis for Integrated Atmospheric ECV Climate Monitoring \\
\hline GCIS ontology & Global Change Information System ontology \\
\hline GCOS & Global Climate Observing System \\
\hline GCOS IP 2016 & Global Climate Observing System Implementation Plan 2016 \\
\hline GEO & Group on Earth Observation \\
\hline GEOSS & Global Earth Observation System of Systems \\
\hline GEV & Generalized Extreme Value \\
\hline GRUAN & GCOS Reference Upper-Air Network \\
\hline ICA\&D & International Climate Assessment and Dataset \\
\hline IPCC & Intergovernmental Panel on Climate Change \\
\hline MERRA & Modern-Era Retrospective analysis for Research and Applications \\
\hline MSMM & Measurement System Maturity Matrix \\
\hline NASA & National Aeronautics and Space Administration \\
\hline NCEP & National Centers for Environmental Prediction \\
\hline NOAA & National Oceanic and Atmospheric Administration \\
\hline PQB & Product Quality Brief \\
\hline PUG & Product User Guidance/Guide \\
\hline QA & Quality assurance \\
\hline QA4ECV & Quality Assurance for Essential Climate Variables \\
\hline QQ-Plot & Quantile-Quantile Plot \\
\hline
\end{tabular}




$\begin{array}{ll}\text { RAOBCORE } & \text { Radiosonde Observation using Reanalysis dataset } \\ \text { RICH } & \text { Radiosonde Innovation Composite Homogenization dataset } \\ \text { RSS } & \text { Remote Sensing Systems } \\ \text { SECTEUR } & \text { Sector Engagement for C3S: Translating European User Requirements } \\ \text { SIS } & \text { Sectoral Information System } \\ \text { SMM } & \text { System Maturity Matrix } \\ \text { SST } & \text { Sea-surface temperature } \\ \text { TCDR } & \text { Thematic Climate Data Record } \\ \text { USCRN } & \text { U.S. Climate Reference Network } \\ \text { ValQI } & \text { Validation Quality Indicator } \\ \text { WCRP } & \text { World Climate Research Programme } \\ \text { WGClimate } & \text { CEOS/CGMS Working Group Climate } \\ \text { WMO } & \text { World Meteorological Organization }\end{array}$

\section{References}

1. Lucio, E.D.F.; Grasso, V. The global framework for climate services (GFCS). Clim. Serv. 2016, 2-3, 52-53. [CrossRef]

2. Hewitt, C.; Mason, S.; Walland, D. The global framework for climate services. Nat. Clim. Chang. 2012, 2, 831. [CrossRef]

3. Mahon, R.; Greene, C.; Cox, S.-A.; Guido, Z.; Gerlak, A.K.; Petrie, J.-A.; Trotman, A.; Liverman, D.; Van Meerbeeck, C.J.; Scott, W.; et al. Fit for purpose? Transforming National Meteorological and Hydrological Services into National Climate Service Centers. Clim. Serv. 2019, 13, 14-23. [CrossRef]

4. European Commission. A European Research and Innovation Roadmap for Climate Services; Directorate-General for Research and Innovation (European Commission): Brussels, Belgium, 2015.

5. Raoult, B.; Bergeron, C.; Lopez-ALos, A.; Thepaut, J.-N.; Dee, D. Climate service develops user-friendly data store. Meteorology 2017, 151, 24-27.

6. Street, R.B. Towards a leading role on climate services in Europe: A research and innovation roadmap. Clim. Serv. 2016, 1, 2-5. [CrossRef]

7. QA4ECV. Quality Assurance for Essential Climate Variables 2014. Available online: http://www.qa4ecv.eu/ (accessed on 17 May 2019).

8. QA4EO. Quality Assurance framework for Earth Observation 2013. Available online: http://www.qa4eo.org/ docs/QA4EO_guide.pdf. (accessed on 17 May 2019).

9. GAIA-CLIM. Gap Analysis for Integrated Atmospheric ECV Climate Monitoring 2014. Available online: http://www.gaia-clim.eu/ (accessed on 17 May 2019).

10. FIDUCEO. Fidelity and Uncertainty in Climate Data Records from Earth Observations. Available online: http://www.fiduceo.eu/ (accessed on 17 May 2019).

11. Su, Z.; Timmermans, W.; Zeng, Y.; Schulz, J.; John, V.O.; Roebeling, R.A.; Poli, P.; Tan, D.; Kaspar, F.; Kaiser-Weiss, A.K.; et al. An overview of European efforts in generating climate data records. Bull. Am. Meteorol. Soc. 2018, 99, 349-359. [CrossRef]

12. ECWMF. C3S_511 Copernicus Climate Change Service-Quality Assessment of ECV Products; ECMWF Copernicus Procurement: Reading, UK, 2016; Available online: https://climate.copernicus.eu/past-tenders (accessed on 17 May 2019).

13. ECWMF. C3S_51 Copernicus Climate Change Service-Evaluation and Quality Control Function for the Climate Data Store; ECMWF Copernicus Procurement: Reading, UK, 2015; Available online: https://climate.copernicus.eu/ past-tenders (accessed on 17 May 2019).

14. ECMWF. C3S_512 Quality Assurance for the Climate Data Store; ECMWF Copernicus Procurement: Reading, UK, 2017; Available online: https://climate.copernicus.eu/past-tenders (accessed on 17 May 2019).

15. ECMWF. C3S_52 Evaluation and Quality Control Function for the Sectoral Information System; ECMWF Copernicus Procurement: Reading, UK, 2015; Available online: https://climate.copernicus.eu/past-tenders (accessed on 17 May 2019).

16. ECMWF. C3S_513 Evaluation and Quality Control Framework for the Sectoral Information System; ECMWF Copernicus Procurement: Reading, UK, 2018; Available online: https://limate.copernicus.eu/past-tenders (accessed on 17 May 2019). 
17. EU-MACS. European Market for Climate Services; EU-MACS: Helsinki, Finland, 2016; Available online: http://eu-macs.eu/eu-macs/ (accessed on 17 May 2019).

18. Hoa, E.; Perrels, A.; Le, T. From generating to using climate services-How the EU-MACS and MARCO projects help to unlock the market potential. Clim. Serv. 2018, 11, 86-88. [CrossRef]

19. MARCO. Market Research for a Climate Services Observatory. Available online: http://marco-h2020.eu/ (accessed on 17 May 2019).

20. EUPORIAS. European Provision of Regional Impacts Assessments on Seasonal and Decadal Timescales. Available online: http://www.euporias.eu/ (accessed on 17 May 2019).

21. Copernicus Climate Change Service. Sectoral Impacts via Sectoral Information System; Copernicus Climate Change Service: Reading, UK, 2015; Available online: https://climate.copernicus.eu/sectoral-impacts (accessed on 17 May 2019).

22. Nightingale, J.; Boersma, K.; Muller, J.-P.; Compernolle, S.; Lambert, J.-C.; Blessing, S.; Giering, R.; Gobron, N.; De Smedt, I.; Coheur, P.; et al. Quality assurance framework development based on six new ECV data products to enhance user confidence for climate applications. Remote Sens. 2018, 10, 1254. [CrossRef]

23. Nightingale, J.; Mittaz, J.; Douglas, S.; Dee, D.; Ryder, J.; Taylor, M.; Old, C.; Dieval, C.; Fouron, C.; Duveau, G.; et al. Ten priority science gaps in assessing climate data record quality. Remote Sens. 2019, 11, 986. [CrossRef]

24. Brasseur, G.P.; Gallardo, L. Climate services: Lessons learned and future prospects. Earth's Future 2016, 4, 79-89. [CrossRef]

25. Larosa, F.; Perrels, A. Assessment of the Existing Resourcing and Quality Assurance of Current Climate Services; EU-MACS: Helsinki, Finland, 2017; Available online: http://eu-macs.eu/wp-content/uploads/2017/07/ EUMACS_D12_v2x.pdf (accessed on 17 May 2019).

26. Otto, J.; Brown, C.; Buontempo, C.; Doblas-Reyes, F.; Jacob, D.; Juckes, M.; Keup-Thiel, E.; Kurnik, B.; Schulz, J.; Taylor, A.; et al. Uncertainty: Lessons learned for climate services. Bul. Am. Meteorol. Soc. 2016, 97, ES265-ES269. [CrossRef]

27. Vaughan, C.; Dessai, S. Climate services for society: Origins, institutional arrangements, and design elements for an evaluation framework. Wiley Interdiscip. Rev. Clim. Chang. 2014, 5, 587-603. [CrossRef] [PubMed]

28. Perrels, A. A Structured Analysis of Obstacles to Uptake of Climate Services and Identification of Policies and Measures to Overcome Obstacles so as to Promote Uptake; EU-MACS: Helsinki, Finland, 2018; Available online: http://eu-macs.eu/wp-content/uploads/2018/12/EUMACS_D51_final-1.pdf (accessed on 17 May 2019).

29. Dowell, M.; Lecomte, P.; Husband, R.; Schulz, J.; Mohr, T.; Tahara, Y.; Eckman, R.; Lindstrom, E.; Wooldridge, C.; Hilding, S.; et al. Strategy Towards an Architecture for Climate Monitoring from Space; World Meteorology Center: Geneva, Switzerland, 2013; p. 39.

30. Yang, W.; John, O.V.; Zhao, X.; Lu, H.; Knapp, R.K. Satellite climate data records: Development, applications, and societal benefits. Remote Sens. 2016, 8, 331. [CrossRef]

31. Vaughan, C.; Dessai, S.; Hewitt, C. Surveying climate services: What can we learn from a bird's-eye view? Weather Clim. Soc. 2018, 10, 373-395. [CrossRef]

32. Vaughan, C.; Buja, L.; Kruczkiewicz, A.; Goddard, L. Identifying research priorities to advance climate services. Clim. Serv. 2016, 4, 65-74. [CrossRef]

33. Bojinski, S.; Verstraete, M.; Peterson, T.C.; Richter, C.; Simmons, A.; Zemp, M. The concept of essential climate variables in support of climate research, applications, and policy. Bull. Am. Meteorol. Soc. 2014, 95, 1431-1443. [CrossRef]

34. Van Den Besselaar, E.J.M.; Klein Tank, A.M.G.; Van Der Schrier, G.; Abass, M.S.; Baddour, O.; Van Engelen, A.F.V.; Freire, A.; Hechler, P.; Laksono, B.I.; Iqbal, I.; et al. International climate assessment \& dataset: Climate services across borders. Bull. Am. Meteorol. Soc. 2015, 96, 16-21. [CrossRef]

35. Schulz, J. Deliverable D2.26 Structured Process for the Generation of Climate Data Records-CORE-CLIMAX Deliverables; EUMETSAT: Darmstadt, Germany, 2015; p. 23. Available online: https://drive.google.com/file/d/ 1QZ_hPCcJsd1R1xJ1ZNg3Iu265sPJserT/view?usp=sharing (accessed on 13 May 2019).

36. Zeng, Y.; Su, Z.; van der Velde, R.; Wang, L.; Xu, K.; Wang, X.; Wen, J. Blending satellite observed, model simulated, and in-situ measured soil moisture over Tibetan plateau. Remote Sens. 2016, 8, 268. [CrossRef]

37. UNFCCC. The Paris Agreement-2015. P.27; UNFCCC: Bonn, Germany, 2017; Available online: http://unfccc. int/paris_agreement/items/9485.php (accessed on 17 May 2019).

38. GCOS. The Global Observing System for Climate: Implementation Needs; GCOS: Geneva, Switzerland, 2016; p. 325. 
39. GCOS. GCOS Climate Monitoring Principles; GCOS: Geneva, Switzerland, 2003.

40. WGClimate. Four-Year Implementation Plan for the Period November 2015 to November 2019 (Version 2)_ECO-WGCL-EOPS-PL-16-0005; WGClimate: Rome, Italy, 2016; pp. 1-10. Available online: http://ceos.org/document_management/Working_Groups/WGClimate/Documents/CM-13_Doc_04-03_JWGCWorkPlan-Report.pdf (accessed on 19 Februery 2017).

41. GCOS. Guideline for the Generation of Datasets and Products Meeting GCOS Requirements; GCOS-143: Geneva, Switzerland, 2010; p. 12.

42. GCOS. Systematic Observation Requirements for Satellite-Based Data Produts for Climate, 2011 Update, Suplemental Details to the Satellite-Based Component of the "Implementation Plan for the Global Observing System for Climate in Support of the UNFCCC (2010 Update)"; GCOS-154: Geneva, Switzerland, 2011; p. 139.

43. Bojinski, S. Response by ESA to GCOS—Results of the Climate Change Initiative Requirements Analysis; European Space Agency, ESRIN: Rome, Italy, 2011; p. 72.

44. Bojinski, S.; Dowell, M.; Eckman, R.; Gichoni, I.G.; Husband, R.; Lecomte, P.; Zhang, W. Satellites for Climate Services: Case Studies for Establishing an Architecture for Climate Monitoring from Space; Joint Publication of WMO and JRC: Geneva, Switzerland, 2015; pp. 1-65. Available online: https://library.wmo.int/pmb_ged/ wmo_1162_en.pdf (accessed on 17 May 2019).

45. Doblas-Reyes, F. EQC Status Overview. In Proceedings of the First C3S (Copernicus Climate Change Service) General Assembly, Toulouse, France, 7-9 March 2017.

46. WGClimate. ECV Inventory Questionnaire Guide; ECO-WGCL-EOPS-TN-16-0022; WGClimate: Rome, Italy, 2016.

47. WMO. The Global Observing System for Climate: Implementation Needs GCOS 200 (GOOS-214); WMO: Geneva, Switzerland, 2016.

48. Wilson, J.; Dowell, M.; Belward, A. European Capacity for Monitoring and Assimilating Space Based Climate Change Observations_Status and Prospects; JRC Scientific and Technical Reports (EUR 24273 EN); European Commission, Joint Research Center, Institute for Environment and Sustainability: Rome, Italy, 2010; p. 47.

49. L'Ecuyer, T.S.; Beaudoing, H.K.; Rodell, M.; Olson, W.; Lin, B.; Kato, S.; Clayson, C.A.; Wood, E.; Sheffield, J.; Adler, R.; et al. The observed state of the energy budget in the early twenty-first century. J. Clim. 2015, 28, 8319-8346. [CrossRef]

50. Rodell, M.; Beaudoing, H.K.; L'Ecuyer, T.S.; Olson, W.S.; Famiglietti, J.S.; Houser, P.R.; Adler, R.; Bosilovich, M.G.; Clayson, C.A.; Chambers, D.; et al. The observed state of the water cycle in the early twenty-first century. J. Clim. 2015, 28, 8289-8318. [CrossRef]

51. Ma, X.; Fox, P.; Tilmes, C.; Jacobs, K.; Waple, A. Capturing provenance of global change information. Nat. Clim. Change 2014, 4, 409-413. [CrossRef]

52. Ma, X.; Zheng, J.G.; Goldstein, J.C.; Zednik, S.; Fu, L.; Duggan, B.; Aulenbach, S.M.; West, P.; Tilmes, C.; Fox, P. Ontology engineering in provenance enablement for the National Climate Assessment. Environ. Model. Soft. 2014, 61, 191-205. [CrossRef]

53. Loew, A.; Bell, W.; Brocca, L.; Bulgin, C.E.; Burdanowitz, J.; Calbet, X.; Donner, R.V.; Ghent, D.; Gruber, A.; Kaminski, T.; et al. Validation practices for satellite-based Earth observation data across communities. Rev. Geophys. 2017, 55, 779-817. [CrossRef]

54. Zeng, Y.; Su, Z.; Calvet, J.C.; Manninen, T.; Swinnen, E.; Schulz, J.; Roebeling, R.; Poli, P.; Tan, D.; Riihelä, A.; et al. Analysis of current validation practices in Europe for space-based climate data records of essential climate variables. Int. J. Appl. Earth Observ. Geoinform. 2015, 42, 150-161. [CrossRef]

55. Merchant, C.J.; Paul, F.; Popp, T.; Ablain, M.; Bontemps, S.; Defourny, P.; Hollmann, R.; Lavergne, T.; Laeng, A.; de Leeuw, G.; et al. Uncertainty information in climate data records from Earth observation. Earth Syst. Sci. Data 2017, 9, 511-527. [CrossRef]

56. GCOS. User Requirements for Observations (OSCAR/Requirements); GCOS Requirements-Observing Systems Capabilities Analysis and Review Tool (OSCAR); GCOS: Geneva, Switzerland, 2015.

57. Schulz, J.; John, V.; Roebeling, R.; Kaiser-Weiss, A.; Swinnen, E.; Tan, D. Deliverable D2.25 European ECV CDR Capacity Assessment Report; CORE CLIMAX Deliverable: Reading, UK, 2015; p. 180. Available online: https://drive.google.com/file/d/1uUf1aREAzJmtteNTLV5TI12skYqBbDhL/view?usp=sharing (accessed on 13 May 2019). 
58. Kaiser-Weiss, A.; Obregon, A.; Poli, P.; Tan, D.; Gregow, H. D5.53 Procedure for Comparing Reanalyses, and Comparing Reanalyses to Assimilated Observations and CDRs; CORE CLIMAX Deliverable: Reading, UK, 2014; pp. 1-45. Available online: https://drive.google.com/file/d/1WMvA86tFQ_eetMPEHqKKJ4p8qdVT2dEr/ view? usp=sharing (accessed on 13 May 2019).

59. EUMETSAT. CORE-CLIMAX System Maturity Matrix Instruction Manual; Deliverable D222, CC/EUM/MAN/13/002; CORE CLIMAX Deliverable: Reading, UK, 2014; p. 41. Available online: https://drive.google.com/file/d/1nvN_9A3MDxpWbuqfQxHgsgc6MdDMJKmt/view?usp=sharing (accessed on 13 May 2019).

60. John, V. Which Data Are Suitable for Your Application Support Tools to Make Choices; CORE-CLIMAX 1st Capacity Building Workshop; CORE CLIMAX Deliverable: Reading, UK, 2013; Available online: https: //drive.google.com/open?id=1OGi7iJ86-Eb8MUxftnFCWceSyFDUKBHs (accessed on 13 May 2019).

61. ECMWF. C3S-311a Collection and Processing of In-Situ Observations; ECMWF Copernicus Procurement: Reading, UK, 2016; Available online: https://climate.copernicus.eu/past-tenders (accessed on 17 May 2019).

62. ECMWF. C3S_312a Production of Essential Climate Variable Datasets Based on Earth Observations; ECMWF Copernicus Procurement: Reading, UK, 2016; Available online: https://climate.copernicus.eu/past-tenders (accessed on 17 May 2019).

63. ECMWF. C3S_312b Essential Climate Variable Products Derived from Observations; ECMWF Copernicus Procurement: Reading, UK, 2016; Available online: https://climate.copernicus.eu/past-tenders (accessed on 17 May 2019).

64. Barmpadimos, I. CORE-CLIMAX Capacity Building Workshop: Extreme EI Niño Events: What Is the Price? CORE CLIMAX Deliverable: Reading, UK, 2014. Available online: https://drive.google.com/open?id= 1glJiaSDw3F5RPQ7zMCoOZ1n4c9nWEQRg (accessed on 17 May 2019).

65. Kloeppinger-Todd, R.; Sharma, M.; Campaigne, J.; Cohen, M.; Collier, B. Innovations in rural and agriculture finance. In IFPRI 2020 Vision in Food, Agriculture, and the Environment, Focus 18; World Bank: Washington, DC, USA, 2010. Available online: http://documents.worldbank.org/curated/en/775001468336854685/Innovationsin-rural-and-agriculture-finance (accessed on 17 May 2019).

66. Trenberth, K. The Climate Data Guide: Niño SST Indices (Niño 1+2, 3, 3.4, 4; ONI and TNI); National Center for Atmospheric Research: Boulder, CO, USA, 2016.

67. Huang, B.; Thorne, P.W.; Banzon, V.F.; Boyer, T.; Chepurin, G.; Lawrimore, J.H.; Menne, M.J.; Smith, T.M.; Vose, R.S.; Zhang, H.-M. Extended Reconstructed Sea Surface Temperature, Version 5 (ERSSTv5): Upgrades, Validations, and Inter-comparisons. J. Clim. 2017, 30, 8179-8205. [CrossRef]

68. Dee, D.P.; Uppala, S.M.; Simmons, A.J.; Berrisford, P.; Poli, P.; Kobayashi, S.; Andrae, U.; Balmaseda, M.A.; Balsamo, G.; Bauer, P.; et al. The ERA-Interim reanalysis: Configuration and performance of the data assimilation system. Quart. J. R. Meteorol. Soc. 2011, 137, 553-597. [CrossRef]

69. Merchant, C.; Embury, O.; Roberts-Jones, J.; Fiedler, E.; Bulgin, C.E.; Corlett, G.k.; Good, S.; McLaren, A.; Rayner, N.A.; Donlon, C. ESA Sea Surface Temperature Climate Change Initiative (ESA SST CCI): Analysis Long Term Product Version 1.1; Centre for Environmental Data Analysis: Chilton, UK, 2016.

70. Golroudbary, V.R.; Zeng, Y.; Mannaerts, C.M.; Su, Z. Response of extreme precipitation to urbanization over the Netherlands. J. Appl. Meteorol. Clim. 2019, 58, 645-661. [CrossRef]

71. Pfaff, B.; McNeil, A. EVIR: Extreme Values in R. R package Version 1.7-4. 2018. Available online: https: //rdrr.io/cran/evir/ (accessed on 17 May 2019).

72. Team, R.C. R: A Language and Environment for Statistical Computing; R Foundation for Statistical Computing: Vienna, Austria, 2017.

73. Okolewski, A.; Rychlik, T. Sharp distribution-free bounds on the bias in estimating quantiles via order statistics. Stat. Probab. Lett. 2001, 52, 207-213. [CrossRef]

74. Poli, P.; Brunel, P. Assessing reanalysis quality with early sounders Nimbus-4 IRIS (1970) and Nimbus-6 HIRS (1975). Adv. Space Res. 2018, 62, 245-264. [CrossRef]

75. Hollmann, R.; Merchant, C.J.; Saunders, R.; Downy, C.; Buchwitz, M.; Cazenave, A.; Chuvieco, E.; Defourny, P.; de Leeuw, G.; Forsberg, R.; et al. The ESA climate change initiative: Satellite data records for essential climate variables. Bull. Am. Meteorol. Soc. 2013, 94, 1541-1552. [CrossRef]

76. Schulz, J.; Albert, P.; Behr, H.D.; Caprion, D.; Deneke, H.; Dewitte, S.; Dürr, B.; Fuchs, P.; Gratzki, A.; Hechler, P.; et al. Operational climate monitoring from space: The EUMETSAT satellite application facility on climate monitoring (CM-SAF). Atmos. Chem. Phys. 2009, 9, 1687-1709. [CrossRef] 
77. Merchant, J.C.; Holl, G.; Mittaz, P.J.; Woolliams, R.E. Radiance Uncertainty characterisation to facilitate climate data record creation. Remote Sens. 2019, 11, 474. [CrossRef]

78. Thorne, P.W.; Allan, R.J.; Ashcroft, L.; Brohan, P.; Dunn, R.J.H.; Menne, M.J.; Pearce, P.R.; Picas, J.; Willett, K.M.; Benoy, M.; et al. Toward an integrated set of surface meteorological observations for climate science and applications. Bull. Am. Meteorol. Soc. 2017, 98, 2689-2702. [CrossRef]

79. Thorne, P.W.; Diamond, H.J.; Goodison, B.; Harrigan, S.; Hausfather, Z.; Ingleby, N.B.; Jones, P.D.; Lawrimore, J.H.; Lister, D.H.; Merlone, A.; et al. Towards a global land surface climate fiducial reference measurements network. Int. J. Clim. 2018, 38, 2760-2774. [CrossRef]

80. JGCM. Evaluation of Measurement Data Guide to the Expression of Uncertainty in Measurement; JGCM: Salem, OR, USA, 2008.

81. Taylor, B.N.; Kuyatt, C.E. Guidelines for evaluating and expressing the uncertainty of NIST measurement results. In NIST Technical Note 1297; Taylor, B.N., Kuyatt, C.E., Eds.; Physics Laboratory, National Institute of Standards and Technology: Gaithersburg, MD, USA, 1994; pp. 1-25.

82. Lawrimore, J. Review of Specific Observing System Activities Related to Observing Systeme Design (GCOS); CBS/OPAG-IOS/OSDW1/Doc 5.4; World Meteorological Organization: Geneva, Switzerland, 2014. Available online: http://www.wmo.int/pages/prog/www/OSY/Meetings/OSDW1/documents/OSDW1-2013-Doc-5.4GCOS.doc (accessed on 17 May 2019).

83. Thorne, P.W.; Madonna, F.; Schulz, J.; Oakley, T.; Ingleby, B.; Rosoldi, M.; Tramutola, E.; Arola, A.; Buschmann, M.; Mikalsen, A.C.; et al. Making better sense of the mosaic of environmental measurement networks: A system-of-systems approach and quantitative assessment. Geosci. Instrum. Methods Data Syst. Discuss. 2017, 1-43. [CrossRef]

84. Bodeker, G.E.; Bojinski, S.; Cimini, D.; Dirksen, R.J.; Haeffelin, M.; Hannigan, J.W.; Hurst, D.F.; Leblanc, T.; Madonna, F.; Maturilli, M.; et al. Reference upper-air observations for climate: From concept to reality. Bull. Am. Meteorol. Soc. 2015, 97, 123-135. [CrossRef]

85. Seidel, D.J.; Berger, F.H.; Immler, F.; Sommer, M.; Vömel, H.; Diamond, H.J.; Dykema, J.; Goodrich, D.; Murray, W.; Peterson, T.; et al. Reference upper-air observations for climate: Rationale, progress, and plans. Bull. Am. Meteorol. Soc. 2009, 90, 361-369. [CrossRef]

86. Diamond, H.J.; Karl, T.R.; Palecki, M.A.; Baker, C.B.; Bell, J.E.; Leeper, R.D.; Easterling, D.R.; Lawrimore, J.H.; Meyers, T.P.; Helfert, M.R.; et al. U.S. Climate reference network after one decade of operations: Status and assessment. Bull. Am. Meteorol. Soc. 2013, 94, 485-498. [CrossRef]

87. Leeper, R.D.; Rennie, J.; Palecki, M.A. Observational Perspectives from U.S. Climate reference network (USCRN) and cooperative observer program (COOP) network: Temperature and precipitation comparison. J. Atmos. Oceanic Technol. 2015, 32, 703-721. [CrossRef]

88. Bates, J.J.; Privette, J.L. A maturity model for assessing the completeness of climate data records. Eos Trans. Am. Geophys. Union 2012, 93, 441. [CrossRef]

89. Matthews, J.L.; Mannshardt, E.; Gremaud, P. Uncertainty quantification for climate observations. Bull. Am. Meteorol. Soc. 2012, 94, ES21-ES25. [CrossRef]

90. Saha, S.; Moorthi, S.; Pan, H.-L.; Wu, X.; Wang, J.; Nadiga, S.; Tripp, P.; Kistler, R.; Woollen, J.; Behringer, D.; et al. The NCEP climate forecast system reanalysis. Bull. Am. Meteorol. Soc. 2010, 91, 1015-1057. [CrossRef]

91. Brönnimann, S.; Allan, R.; Atkinson, C.; Buizza, R.; Bulygina, O.; Dahlgren, P.; Dee, D.; Dunn, R.; Gomes, P.; John, V.O.; et al. Observations for reanalyses. Bull. Am. Meteorol. Soc. 2018, 99, 1851-1866. [CrossRef]

92. Buizza, R.; Brönnimann, S.; Haimberger, L.; Laloyaux, P.; Martin, M.J.; Fuentes, M.; Alonso-Balmaseda, M.; Becker, A.; Blaschek, M.; Dahlgren, P.; et al. The EU-FP7 ERA-CLIM2 Project contribution to advancing science and production of Earth system climate reanalyses. Bull. Am. Meteorol. Soc. 2017, 99, 1003-1014. [CrossRef]

93. Poli, P.; Hersbach, H.; Tan, D.; Dee, D.; Thépaut, J.-N.; Simmons, A.; Peubey, C.; Laloyaux, P.; Komori, T.; Berrisford, P.; et al. The Data Assimilation System and Initial Performance Evaluation of the ECMWF Pilot Reanalysis of the 20th-Century Assimilating Surface Observations Only (ERA-20C); ECMWF Technical Report; ECMWF: Reading, UK, 2013; p. 59.

94. Poli, P.; Hersbach, H.; Dee, D.P.; Berrisford, P.; Simmons, A.J.; Vitart, F.; Laloyaux, P.; Tan, D.G.H.; Peubey, C.; Thépaut, J.-N.; et al. ERA-20C: An atmospheric reanalysis of the twentieth century. J. Clim. 2016, 29, 4083-4097. [CrossRef] 
95. Hersbach, H.; Peubey, C.; Simmons, A.; Poli, P.; Dee, D.; Berrisford, P. ERA-20CM: A Twentieth Century Atmospheric Model Ensemble; ECMWF Technical Report; ECMWF: Reading, UK, 2013; p. 44.

96. Simmons, A.; Poli, P.; Dee, D.; Berrisford, P.; Hersbach, H.; Peubey, C. Estimating Low-Frequency Variability and Trends in Atmospheric Temperature Using ERA-Interim; ECMWF Technical Report; ECMWF: Reading, UK, 2013; p. 48.

97. Poli, P.; Tan, D.; John, V.; Schulz, J. Procedure for Feeding Back Improved Ancillary Data to Assist Climate Data Records Updates; European Union Seventh Framework Programme CORE-CLIMAX: Reading, UK, 2013; p. 14. Available online: https://drive.google.com/file/d/1BpCuyNHn3faDKDjg_kN5t0fEjIKatH5j/view?usp=sharing (accessed on 17 May 2019).

98. Tan, D.; Poli, P. Design of Support Infrastructure for CDR Quality Assessment in a Reanalysis Environment; European Union Seventh Framework Programme CORE-CLIMAX: Reading, UK, 2013; p. 27. Available online: https://rive.google.com/file/d/1LQdrqNN9uVPG9czulannBbKQb9GHGzud/view?usp=sharing (accessed on 17 May 2019).

99. Tan, D.; Poli, P.; Schulz, J. Procedures for Feeding back Reanalysis Results and Plans to CDR Producers; European Union Seventh Framework Programme CORE-CLIMAX: Redaing, UK, 2014; p. 16. Available online: https://drive.google.com/file/d/1uN2r3Z0LpjSyWqPU7Vjln6XPcjkThLY-/view?usp=sharing (accessed on 17 May 2019).

100. Kaiser-Weiss, A.K.; Kaspar, F.; Heene, V.; Borsche, M.; Tan, D.G.H.; Poli, P.; Obregon, A.; Gregow, H. Comparison of regional and global reanalysis near-surface winds with station observations over Germany. Adv. Sci. Res. 2015, 12, 187-198. [CrossRef]

101. Bosilovich, M.G.; Kennedy, J.; Dee, D.; Allan, R.; O’Neill, A. On the reprocessing and reanalysis of observations for climate. In Climate Science for Serving Society; Asrar, G.R., Hurrell, J.W., Eds.; Springer: Dordrecht, Germany, 2013; pp. 51-72.

102. Bosilovich, M.; Thepaut, J.-N.; Onogi, K.; Kumar, A.; Dee, D.; Brown, O. WCRP Task Team for Inter-comparison of ReAnalyses (TIRA): A White Paper Outlining the Need for Reanalysis Inter-Comparison Guidance and Task Team at an International Level. Available online: https://reanalyses.org/sites/default/files/groups/users/ michael.bosilovich/TIRA_WDAC_v1b.pdf (accessed on 17 May 2019).

103. Lourenço, T.C.; Swart, R.; Goosen, H.; Street, R. The rise of demand-driven climate services. Nat. Clim. Change 2015, 6, 13-14. [CrossRef]

104. Trenberth, K.E.; Anthes, R.A.; Belward, A.; Brown, O.B.; Habermann, T.; Karl, T.R.; Running, S.; Ryan, B.; Tanner, M.; Wielicki, B. Challenges of a sustained climate observing system. In Climate Science for Serving Society; Asrar, G.R., Hurrell, J.W., Eds.; Springer: Dordrecht, Germany, 2013; pp. 13-50.

105. Buontempo, C.; Hewitt, C. EUPORIAS and the development of climate services. Clim. Serv. 2017. [CrossRef]

106. Christel, I.; Hemment, D.; Bojovic, D.; Cucchietti, F.; Calvo, L.; Stefaner, M.; Buontempo, C. Introducing design in the development of effective climate services. Clim. Serv. 2017. [CrossRef] 